\title{
Lack of Westerly Wind Bursts in Unmaterialized EI Niño Years
}

\author{
AYAKO SEIKI \\ Department of Coupled Ocean-Atmosphere-Land Processes Research, \\ Japan Agency for Marine-Earth Science and Technology, Yokosuka, Japan \\ YUKARI N. TAKAYABU \\ Atmosphere and Ocean Research Institute, The University of Tokyo, \\ Kashiwa, Japan \\ TAKUYA HASEGAWA \\ Research and Development Center for Global Change, Japan Agency for \\ Marine-Earth Science and Technology, Yokosuka, Japan \\ KUNIO YONEYAMA \\ Department of Coupled Ocean-Atmosphere-Land Processes Research, Japan Agency \\ for Marine-Earth Science and Technology, Yokosuka, Japan
}

(Manuscript received 4 May 2017, in final form 26 September 2017)

\begin{abstract}
The lack of westerly wind bursts (WWBs) when atmospheric intraseasonal variability (ISV) events occur from boreal spring to autumn is investigated by comparing two types of El Niño years with unmaterialized El Niño (UEN) years. Although high ocean heat content buildup and several ISV events propagating eastward are observed in all three types of years, few WWBs accompany these in the UEN years. The eddy kinetic energy budget analysis based on ISV shows that mean westerly winds in the lower troposphere facilitate the development of eddy disturbances, including WWBs, through convergence and meridional shear of zonal winds. In the UEN years, these westerly winds are retracted westward and do not reach the equatorial central Pacific mainly as a result of interannual components. In addition, positive sea surface temperature anomalies in the western Pacific, which are conducive to active convection, spread widely in a meridional direction centered on $15^{\circ} \mathrm{N}$. Both westward-retracted mean westerlies and off-equatorial warming enhance offequatorial eddies, which result in a reduction in equatorial eddies such as WWBs. The characteristics of the UEN years are significantly different from those observed during the eastern Pacific El Niño (EP-EN) years, which are characterized by anomalous cooling (warming) and suppressed (enhanced) convective eddies in the off-equatorial (equatorial) western Pacific. The central Pacific El Niño years show mixed features during both EP-EN and UEN years. Different background states not only in the equatorial region but also in the offequatorial region can be a reason for the lack of WWBs in the UEN years.
\end{abstract}

\section{Introduction}

El Niño-Southern Oscillation (ENSO) is the dominant interannual variability in the tropical Pacific, seriously affecting global climates and society. Sustained efforts made by the scientific community in recent decades have led to significant progress in understanding that ENSO mainly consists of ocean-atmosphere interaction (Bjerknes 1969). Subsequent oscillator theories

Corresponding author: Ayako Seiki, aseiki@jamstec.go.jp have been proposed to improve on Bjerknes's theory. These include the delayed oscillator theory (e.g., Schopf and Suarez 1988), the western Pacific oscillator theory (e.g., Weisberg and Wang 1997), and the advectivereflective oscillator theory (Picaut et al. 1997), which are based on equatorial wave dynamics, and fourth, the recharge-discharge oscillator theory (Jin 1997), which is based on poleward-equatorward ocean heat transports. Although there is a general understanding of the concept of ENSO, its irregular periodicity, amplitude, and spatial pattern are not fully understood. Although the ocean heat 
content (OHC) buildup along the equator is known to develop necessary conditions for El Niño (e.g., Wyrtki 1975; Zebiak 1989; Kessler 1990; Meinen and McPhaden 2000; Hasegawa and Hanawa 2003), it is not sufficient for predicting every El Niño event (McPhaden 2004). This is especially evident with El Niño events that occurred after 2000 (McPhaden et al. 2011; Horii et al. 2012). One of the factors that explains the irregularity of ENSO is the high-frequency atmospheric forcing along the equator called westerly wind bursts (WWBs). WWBs are synoptic-scale westerly winds that blow over the surface near the equator. These winds can force strong eastward currents that advect warm surface water from the western Pacific to the central Pacific. In addition, WWBs can excite oceanic downwelling Kelvin waves along the equator that propagate eastward and depress the thermocline, resulting in positive sea surface temperature (SST) anomalies in the eastern Pacific where the thermocline is normally shallow (e.g., McPhaden and Taft 1988; Kessler et al. 1995; Lengaigne et al. 2002).

WWB occurrences accompany organized convection and cyclonic flows in the lower troposphere around the equator (e.g., Harrison and Vecchi 1997; Seiki and Takayabu 2007a,b, hereafter ST07a,b). The dominant intraseasonal variability (ISV) in the tropical atmosphere is the Madden-Julian oscillation (MJO), which propagates eastward around the equator with organized convection and circulation anomalies especially over the warm pool (e.g., Madden and Julian 1994; Zhang 2005). Although the $\mathrm{MJO}$ is known as planetary-scale variability, it has hierarchal structures such as eastwardmoving cloud clusters and westward-moving synoptic disturbances (e.g., Nakazawa 1988). The eastwardpropagating intraseasonal convection such as the MJO is accompanied by WWBs in some cases (e.g., Nitta et al. 1992; Sui and Lau 1992; Lin and Johnson 1996). A statistical analysis (ST07a,b) showed that large-amplitude intraseasonal convection is favorable but not sufficient for WWB generation because background winds and SST also play an important role in WWB occurrences. These studies show that synoptic eddies such as the WWBs within the ISV convective envelope develop over the equatorial central Pacific and result in WWB generation during the El Niño developing phases. When these eddies develop far from the equator during other ENSO phases, they neither generate equatorial WWBs nor exert an influence on El Niño. Seiki et al. (2009) also showed that the MJO events during the El Niño developing phases excite strong oceanic downwelling Kelvin waves, while they excite weak upwelling Kelvin waves during other ENSO phases, which originate from different background wind states. The modulation of
WWB occurrences by warm pool displacements related to ENSO has also been mentioned in recent modeling studies (e.g., Eisenman et al. 2005; Gebbie et al. 2007; Kug et al. 2008), and WWBs are sometimes called the state-dependent noise. Puy et al. (2016) indicated that not only the MJO but also convectively coupled Rossby waves can modulate WWB occurrences.

The association between ENSO's irregularity and the diversity of El Niño events has received wide attention recently. Classical El Niño events that have their largest anomalous warming in the eastern Pacific and their cooling in the western Pacific have been called the eastern Pacific El Niño (EP-EN) or canonical El Niño. This differentiates these events from a new type of El Niño, referred to as the central Pacific El Niño (CP-EN), El Niño Modoki, date line El Niño, or warm pool El Niño (Kao and Yu 2009; Ashok et al. 2007; Kug et al. 2009; Larkin and Harrison 2005). CP-EN is characterized by significant warming in the central Pacific flanked by relative cooling on both sides. The state-dependent noise (i.e., WWBs) included in a coupled general circulation model increased persistent El Niño events such as EP-EN and not CP-EN (Lopez and Kirtman 2014). Although these two types of El Niño have different teleconnection patterns (e.g., Weng et al. 2009; Kim et al. 2009), it is still controversial whether CP-EN is an independent mode or a phase of El Niño events (e.g., Giese and Ray 2011; Lian and Chen 2012; Takahashi et al. 2011). Irrespective of whether CP-EN is a mode or a phase, CP-EN events have increased since 2000. Decreased variations in $\mathrm{OHC}$ and weak interrelationships between preceding OHC buildup and subsequent El Niño occurrences that occurred after 2000 may be related to the frequent occurrences of CP-EN (McPhaden et al. 2011; Horii et al. 2012). Fedorov et al. (2015) examined the relationships among initial $\mathrm{OHC}$, the presence of WWBs, and the resulting El Niño type by using a coupled general circulation model. They showed that high OHC with (without) WWBs results in EP-EN (CP-EN) and that normal OHC with (without) WWBs leads to CP-EN (weak La Niña). Jadhav et al. (2015) indicated that high OHC without WWBs leads to a basinwide warming pattern. A clustering analysis undertaken by Chen et al. (2015) showed that several patterns are found in El Niño depending on the presence of WWBs, but there is only one pattern of La Niña. Based on the studies above, all El Niño events in this study are classified into EP-EN and CP-EN.

The most outstanding El Niño event in recent decades occurred in 1997/98. During this period, there were a high-OHC buildup and an extraordinary eastward shift of the warm pool with successive WWBs. Since the high $\mathrm{OHC}$ and successive equatorial WWBs observed in early 
2014 were similar to conditions recorded in 1997, many research institutes in the world predicted that a strong El Niño would occur in late 2014. However, a marginal El Niño occurred in late 2014, which developed again in 2015. This event was not anticipated and, therefore, generated much attention among the scientific community (e.g., McPhaden 2015). One of the reasons addressed is the lack of WWBs after boreal spring in 2014 (Menkes et al. 2014). Min et al. (2015) and Maeda et al. (2016) also indicated that anomalous easterly or southeasterly winds around the equator observed in the boreal summer of 2014 caused upwelling and/or evaporative cooling, resulting in cooling of the eastern Pacific. Levine and McPhaden (2016) documented that these easterly winds not only inhibited the El Niño development in 2014 but also enhanced the 2015 El Niño event by inhibiting the discharge of the equatorial OHC. In addition, Imada et al. (2016) used a general circulation model to show that cold subsurface water in the tropical South Pacific that penetrated the equatorial region played an important role in cooling the equatorial Pacific in 2014. Many of the studies mentioned above suggest that interdecadal variability such as the interdecadal Pacific oscillation (IPO; e.g., Power et al. 1999) contributed to the foundation of negative SST anomalies in the tropical Pacific.

In this study, the factors that caused the lack of WWBs when ISV convection is evident over the tropical western and central Pacific from boreal spring to autumn, corresponding to a developing phase of El Niño, are examined. The study focuses on background states and compares the EP-EN and CP-EN years with unmaterialized El Niño (UEN) years that had high-OHC buildup early in the year. Hereafter, The EP-EN, CP-EN, and UEN years are referred to collectively as the high-OHC years. In addition, neutral OHC (NTL) years are also examined to compare with three types of the high-OHC years.

The rest of this paper is organized as follows: The datasets and definitions of the El Niño years, ISV events, and WWBs that were used in this study are described in section 2 . Section 3 provides energetics during the ISV's westerly periods and its relation with ENSO. In section 4, background states in the EP-EN, CP-EN, UEN, and NTL years are compared, concentrating on their contributions to the energetics in the equatorial and off-equatorial areas. Case analysis of the 2014 and 2015 events is performed in section 5. The final section provides a summary and discussion.

\section{Data and methodology}

\section{a. Data}

Atmospheric datasets for the period 1982-2015 are obtained from the Japanese 55-year Reanalysis (JRA55; Kobayashi et al. 2015) provided by the Japan
Meteorological Agency. Zonal and meridional winds ( $u$ and $v$, respectively), pressure vertical velocity $\omega$, pressure $p$, temperature $T$, and geopotential $\Phi$ at pressure levels from 1000 to $100 \mathrm{hPa}$; $10-\mathrm{m}$ winds; sea level pressure; and velocity potential at $200 \mathrm{hPa}$ are recorded four times daily with a horizontal resolution of $1.25^{\circ}$. Mean daily values of these data are used.

As a measure of $\mathrm{OHC}$ in the equatorial Pacific, monthly anomalies of equatorial warm water volume (WWV) defined as the anomalous volume of water integrated between $120^{\circ} \mathrm{E}$ and $80^{\circ} \mathrm{W}$ from $5^{\circ} \mathrm{N}$ to $5^{\circ} \mathrm{S}$ from sea surface to the depth of the $20^{\circ} \mathrm{C}$ isotherm are used. These data are derived from the ocean analyses of the Bureau National Operations Centre at the Australian Bureau of Meteorology and obtained from the National Oceanic and Atmospheric Administration (NOAA)/Pacific Marine Environmental Laboratory website (http://www.pmel.noaa.gov/tao/wwv/data/). This product is based on temperature profiles from the Tropical Atmosphere and Ocean (TAO) Triangle TransOcean Buoy Network (TRITON) moored buoy array, Argo floats, and expendable bathythermographs. Daily optimum interpolation SST high-resolution datasets, provided by the NOAA/Office of Oceanic and Atmospheric Research/Earth System Research Laboratory Physical Sciences Division, on $0.25^{\circ} \times 0.25^{\circ}$ grids (Reynolds et al. 2007) are used for calculating Niño-3.4 $\left(5^{\circ} \mathrm{N}-5^{\circ} \mathrm{S}, 120^{\circ}-170^{\circ} \mathrm{W}\right) \mathrm{SST}$ anomalies and a composite analysis. In addition, monthly sea level anomalies (SLA) produced by Archiving, Validation, and Interpretation of Satellite Oceanographic Data (AVISO; http://www. aviso.altimetry.fr) on $1.0^{\circ} \times 1.0^{\circ}$ grids are used. All oceanic data cover the period 1982-2015, except for SLA, which are available from 1993 to 2015. Monthly anomalies are calculated as deviations from the monthly climatology.

\section{b. Definitions of EP-EN, CP-EN, UEN, and NTL years}

El Niño years in this study are defined when the 5-month running-mean Niño-3.4 SST anomalies exceed $0.5^{\circ} \mathrm{C}$ in amplitude for more than three consecutive months. The El Niño years are classified into EP-EN and CPEN years based on the definition by Ren and Jin (2011) and McPhaden et al. (2011) using the Niño-3 $\left(5^{\circ} \mathrm{N}-5^{\circ} \mathrm{S}, 150^{\circ}-90^{\circ} \mathrm{W}\right)$ and Niño- $4\left(5^{\circ} \mathrm{N}-5^{\circ} \mathrm{S}, 160^{\circ} \mathrm{E}-\right.$ $\left.150^{\circ} \mathrm{W}\right) \mathrm{SST}$ anomalies. According to their definition, the $1982 / 83,1986 / 87,1991 / 92,1997 / 98,2006 / 07$, and 2015/16 events are classified as EP-EN, and the other El Niño events (1994/95, 2002/03, 2004/05, and 2009/10) are classified as CP-EN. Figure 1 shows 5-month running means of the WWV anomalies and the Niño-3.4 SST anomalies. The El Niño events, shown by arrows, follow 

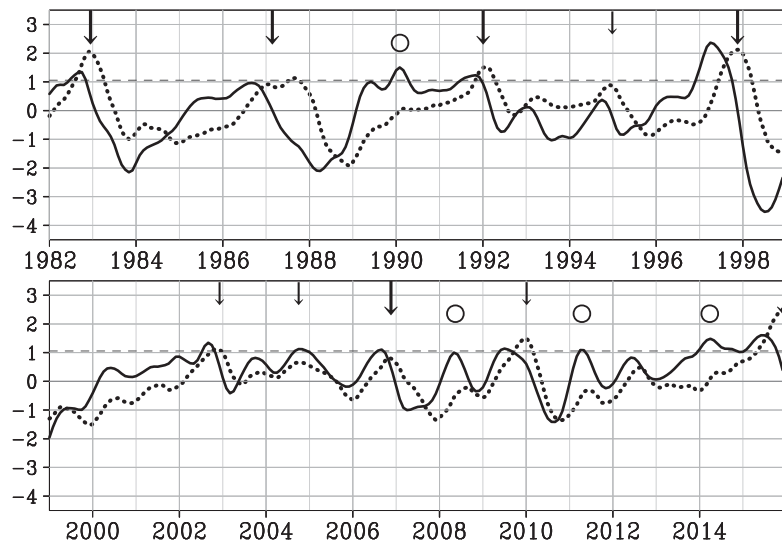

FIG. 1. The 5-month running means of WWV anomalies $\left(10^{14} \mathrm{~m}^{3}\right.$; solid lines) and Niño-3.4 SST anomalies ( ${ }^{\circ} \mathrm{C}$; dotted lines). Dashed gray lines show the standard deviation for WWV anomalies. Large and small arrows indicate EP-EN and CP-EN years, respectively. Circles represent the UEN years defined in this study.

the positive peaks of the WWV anomalies, as is indicated in the previous studies. A close inspection of Fig. 1 shows high WWV years other than El Niño years. In this study, the UEN years (1990, 2008, 2011, and 2014) are defined when the 5-month running-mean WWV anomalies exceed one standard deviation and the following Niño-3.4 SST anomalies do not meet the El Niño criteria. Note that the 2014 El Niño is identified as a UEN year in this study because of its peculiar developing process without a clear peak in Niño-3.4 SST anomalies, in which the SST anomalies marginally exceeded the El Niño criteria at the end of 2014 and stayed marginal for several months (Fig. 1). In addition, the NTL years $(1985,1996,2000,2001,2003$, and 2013) are defined when the 5-month running-mean WWV anomalies early in the year remain within a range from -0.5 to +0.5 standard deviation to compare with three types of the high-OHC years, especially the UEN years.

\section{c. Atmospheric ISV events}

To detect the signals of atmospheric ISV, velocity potential at $200 \mathrm{hPa}$ obtained from JRA-55 are bandpass filtered (BPF) with half-power frequency cutoffs at 20 100 days. The BPF velocity potential in the upper troposphere has been known to represent a large-scale divergence and be a good index of the ISV's convective signals (e.g., Knutson and Weickmann 1987; Slingo et al. 1999). The present study focuses on the ISV events observed from boreal spring to autumn corresponding to the El Niño developing phases. The 47 and 14 ISV events are detected in the high-OHC years and the NTL years, respectively, from April to September when the amplitudes of the negative BPF velocity potential
TABLE 1. Minimum, maximum, and averaged numbers of ISV events per six months (April-September) and the total ISV number detected during the six months in the EP-EN, CP-EN, UEN, and NTL years.

\begin{tabular}{lcccc}
\hline \hline & Min No. & Max No. & Avg No. & Total \\
\hline EP-EN & 2 & 5 & 3.0 & 18 \\
CP-EN & 3 & 5 & 3.5 & 14 \\
UEN & 3 & 4 & 3.5 & 14 \\
NTL & 1 & 4 & 2.3 & 14 \\
\hline
\end{tabular}

averaged over the western Pacific $\left(10^{\circ} \mathrm{N}-10^{\circ} \mathrm{S}, 120^{\circ} \mathrm{E}-\right.$ $180^{\circ}$ ) exceed one standard deviation. A major indicator of the MJO is an all-season real-time multivariate MJO (RMM) index (Wheeler and Hendon 2004), which is well known but not perfect (e.g., Straub 2013) as it missed some convective ISV events as a result of technical reasons. Additionally, the MJO is usually weak during boreal summer (e.g., Madden 1986; Zhang and Dong 2004), which is included in our focused season (April-September), although northward-propagating ISV convection called boreal summer intraseasonal oscillation (BSISO; e.g., Wang and Rui 1990; Lawrence and Webster 2002) is active in the season. In this study, we do not use the RMM index primarily because we focus on all organized large-scale ISV convection, which is known to be a preferable condition for WWB occurrences, regardless of whether the ISV convection is strictly defined as the MJO. Note that $87.0 \%$ of the ISV events detected in this study are defined as the MJO as the amplitude of the RMM index exceeds 1.0 over the Pacific (i.e., the RMM phases 4-7) in five days before and after the BPF velocity potential minima. In addition, all but two ISV events apparently propagate eastward when checked by the timelongitude section of BPF velocity potential.

Basically, the eastward-propagating ISV convection precedes (follows) the low-level westerly (easterly) wind anomalies, and synoptic disturbances such as tropical cyclones frequently develop in the westerly periods (e.g., Liebmann et al. 1994; Maloney and Hartmann 2000). Therefore, the westerly periods of the ISV, which is the favorable ISV condition for synoptic eddies, is focused on in this study. The centers of the westerly periods are determined by the nearest maxima of 20 100 days BPF zonal winds at $850 \mathrm{hPa}$ simultaneously with or following the minimum of the BPF velocity potential. Note that one event in 1997 is excluded because there is no westerly peak around the minimum of the BPF velocity potential. Table 1 shows the numbers of ISV events with westerly peaks for each 6-month period and the total ISV numbers during the EP-EN, CP-EN, UEN, and NTL years. The minimum, maximum, and average numbers of the EP-EN, CP-EN, and UEN years 
TABLE 2. Accumulated numbers of WWB occurrence days over the western and central Pacific from April to September in each year and the averaged numbers for EP-EN, CP-EN, UEN, and NTL years. The numbers of WWB events detected in this study are shown in parentheses.

\begin{tabular}{|c|c|c|c|c|c|c|c|}
\hline \multicolumn{2}{|c|}{ EP-EN } & \multicolumn{2}{|c|}{ CP-EN } & \multicolumn{2}{|c|}{ UEN } & \multicolumn{2}{|c|}{ NTL } \\
\hline Year & WWB days & Year & WWB days & Year & WWB days & Year & WWB days \\
\hline 1982 & $54(14)$ & 1994 & $10(3)$ & 1990 & $4(2)$ & 1985 & $0(0)$ \\
\hline 1986 & $24(6)$ & 2002 & $41(9)$ & 2008 & $0(0)$ & 1996 & $3(1)$ \\
\hline 1991 & $11(3)$ & 2004 & $15(5)$ & 2011 & $4(1)$ & 2000 & $0(0)$ \\
\hline 1997 & $94(21)$ & 2009 & $10(3)$ & 2014 & $7(3)$ & 2001 & $8(1)$ \\
\hline 2006 & $15(6)$ & - & - & - & - & 2003 & $8(2)$ \\
\hline 2015 & 64 (12) & - & - & - & - & 2013 & $0(0)$ \\
\hline Avg & $43.7(10.3)$ & Avg & $19.0(5.0)$ & Avg & $3.8(1.5)$ & Avg & $3.2(0.7)$ \\
\hline
\end{tabular}

do not differ significantly from each other. This result indicates that interannual variability of the ISV during the high-OHC years, in terms of the number, is independent of ENSO variability. During the NTL years, the number of ISV events is somewhat lower than that of the high-OHC years.

\section{d. WWB occurrences over the western and central Pacific}

In this study, WWBs are identified when daily surface zonal wind anomalies averaged for the equatorial region $\left(2.5^{\circ} \mathrm{N}-2.5^{\circ} \mathrm{S}\right)$ exceed $5.0 \mathrm{~m} \mathrm{~s}^{-1}$ at each grid point. In addition, these wind anomalies must cover $10^{\circ}$ longitude or more for at least two days (see ST07a,b for further details). The wind anomalies are deviations from the mean seasonal cycle, defined as a 91-day running-mean daily climatology. The wind threshold of $5.0 \mathrm{~m} \mathrm{~s}^{-1}$ is determined to extract extreme events, and this threshold corresponds to 2.84 standard deviations. The accumulated numbers of WWB days over the western and central Pacific $\left(120^{\circ} \mathrm{E}-160^{\circ} \mathrm{W}\right)$ from boreal spring to autumn in the EP-EN and CP-EN years range from 10 to 94 days (Table 2). Conversely, there are fewer WWB days in the UEN and NTL years: eight days or less. The average numbers of the accumulated WWB days in the EP-EN, CP-EN, UEN, and NTL years show outstanding differences. The EP-EN (CP-EN) years have more than 10 (5) times as many WWB days compared to the averaged WWB days in the UEN/NTL years. This result indicates that WWB frequency has interannual variability related with ENSO, which is consistent with the previous results (e.g., Harrison and Vecchi 1997; ST07a). The number of WWB events detected in this study is shown in parentheses. General characteristics such as differences among the average numbers for EPEN, CP-EN, UEN, and NTL years are similar to the accumulated WWB days. However, in some El Niño years and UEN years $(1991,1994,2009$, and 2014), although the same number, three, of WWB events is counted, there are more accumulated WWB days observed in El Niño years than in the UEN years. This is because WWB events in El Niño years have longer durations than those in the UEN years. Whereas there is a small interannual difference found within the ISV events (Table 1), WWB occurrence days have strong interannual variability (Table 2 ). These results confirm insignificant correlations between the MJO and ENSO (e.g., Slingo et al. 1999) and indicate that the ISV events are preferable, but not sufficient, for WWB occurrences, as mentioned in ST07a,b.

\section{Energetics during the ISV's westerly periods}

To isolate synoptic disturbances such as WWBs within the ISV convective envelope, all variables are decomposed into mean and eddy components. A variable with an overbar indicates that its mean (low frequency) components are defined as an 11-day running mean, which represents intraseasonal time scales and longer. The eddy components with periods shorter than the ISV are defined as deviations from the 11-day running mean and are represented with a prime. Figure 2 shows composite eddy kinetic energy (EKE) at $850 \mathrm{hPa}$ based on the ISV's westerly periods during the EP-EN, CP-EN, UEN, and NTL years. Here, EKE is defined as

$$
K^{\prime}=\frac{1}{2}\left(\overline{u^{\prime 2}}+\overline{v^{\prime 2}}\right)
$$

Hereafter, statistical significances of composite results are examined using the Student's $t$ test. High-EKE values extend from the north of the Philippines to the equatorial central Pacific during the EP-EN and CP-EN years, whereas during the UEN and NTL years, they retreat westward and lie over the off-equatorial western Pacific and the South China Sea. Figure 3 shows the differences of EKE between the EP-EN/CP-EN and 

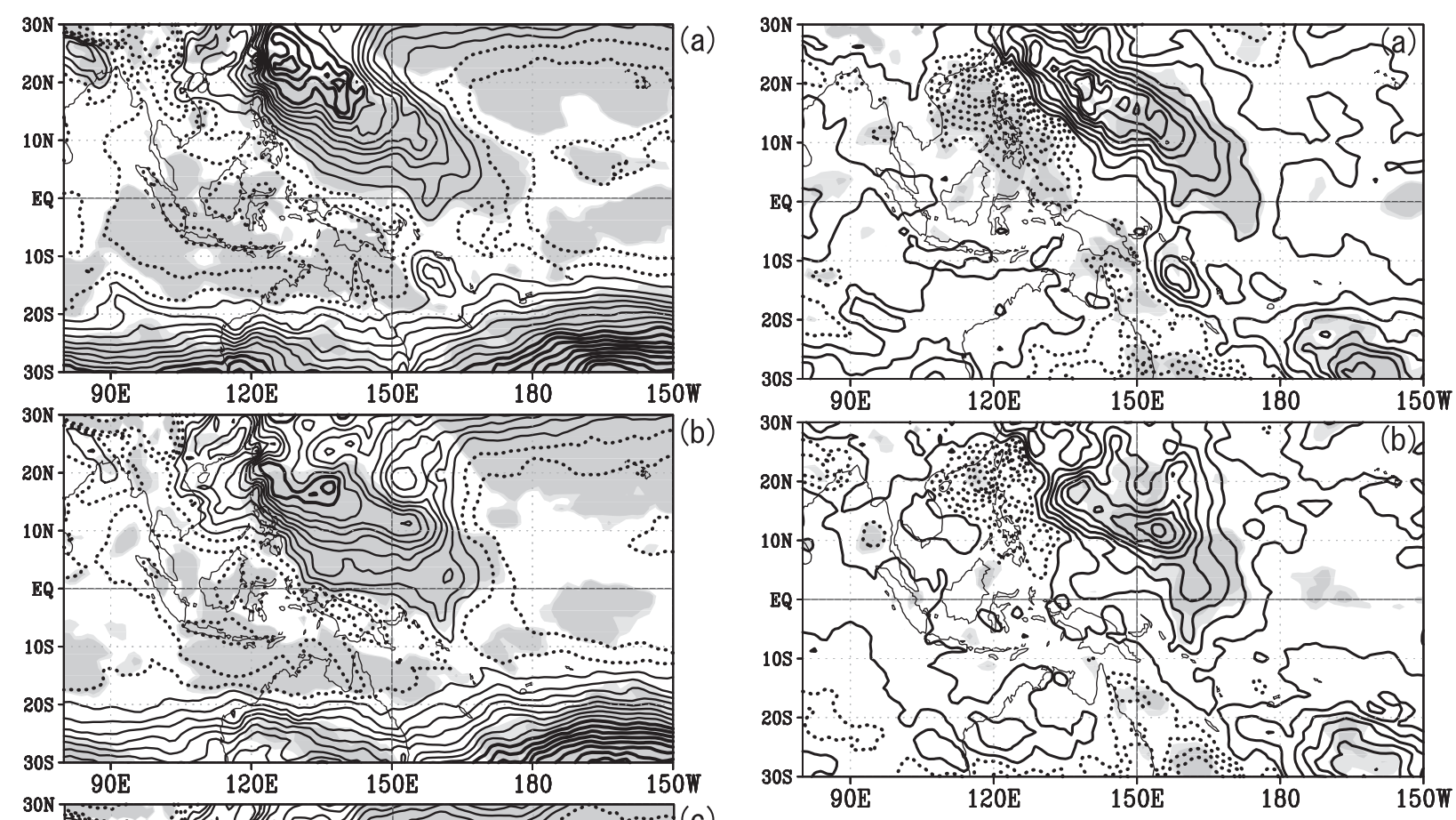

FIG. 3. Differences of composite EKE at $850 \mathrm{hPa}$ between the (a) EP-EN and UEN and (b) CP-EN and UEN years with intervals of $2.0 \mathrm{~m}^{2} \mathrm{~s}^{-2}$. Positive values are represented by solid contours, which indicate larger EKE in the EP-EN or CP-EN years. Dark (light) shading indicates more than $95 \%$ (90\%) significance level using the two-sample Student's $t$ test.

values north of the Philippines are higher in the UEN years. In addition, higher values also appear in the central South Pacific in the EP-EN and CP-EN years, although the significance levels of composite differences in this region are relatively low. The higher EKE values that straddle the equator can lead to twin cyclonic disturbances, resulting in strong WWB events (e.g., Keen 1982; Nitta 1989; ST07a,b). Therefore, these results are consistent with frequent WWB occurrences observed during the EP-EN and CP-EN years (Table 2) and confirm that high-frequency (eddy) components dominate when WWBs occur, although low-frequency westerly wind anomalies induced by the Bjerknes feedback during El Niño events are somewhat included in the definition of WWBs. Around the Philippines, there is less EKE difference between the CP-EN and UEN years with lower significance levels (Fig. 3b) compared to the EP-EN and UEN years (Fig. 3a), indicating that the CP-EN years have relatively similar characteristics to the UEN years in this region.

To examine the mechanisms of EKE distributions, the

UEN years more clearly. Larger EKE values in the EPEN or CP-EN years compared to those in the UEN years are located along a southeast-northwest axis beginning from $170^{\circ} \mathrm{E}$ near the equator, whereas EKE EKE budget analysis is performed. The EKE equation in this study is the same as that used in ST07b and is written as 

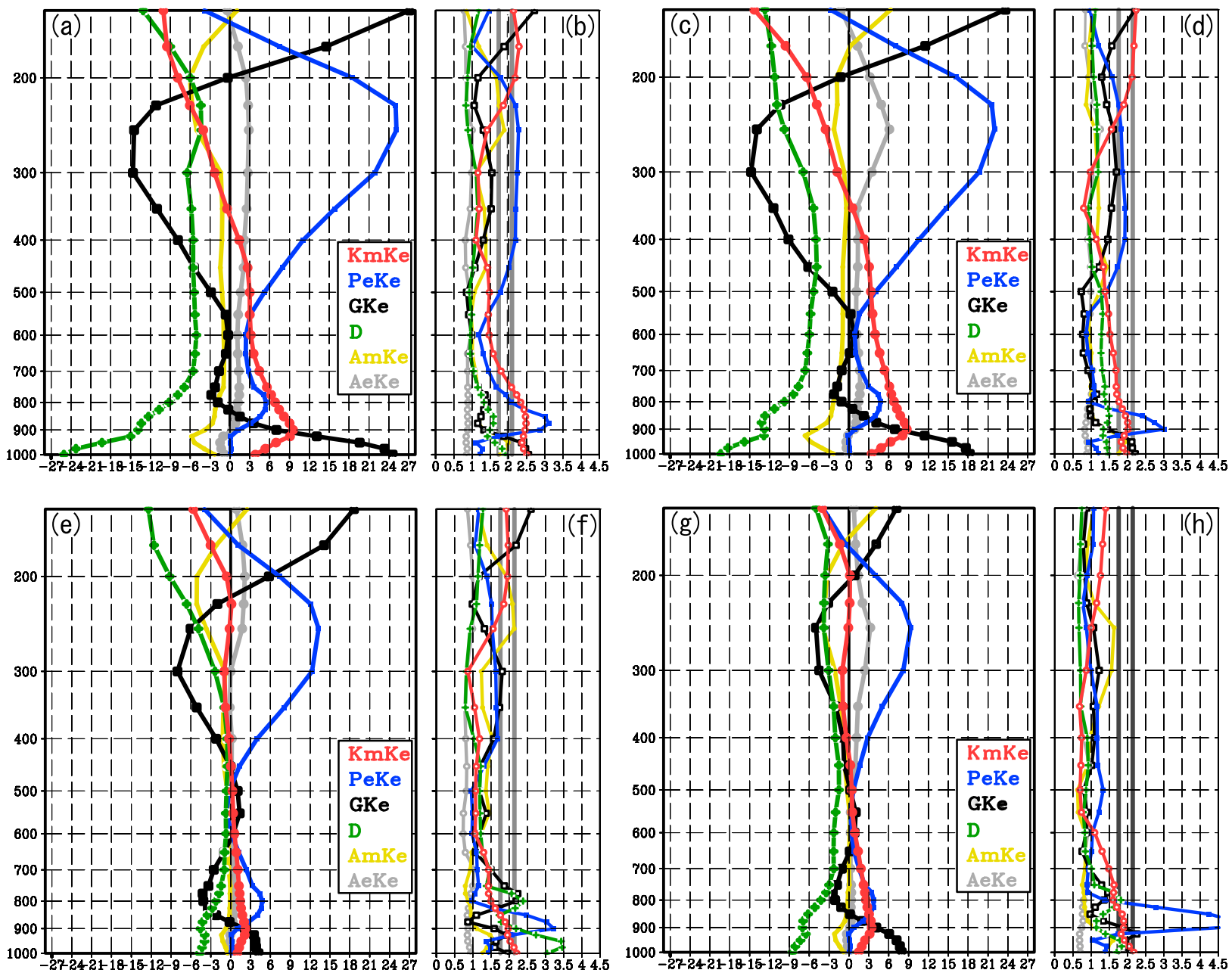

FIG. 4. Composite vertical structures of each term $\left(10^{-5} \mathrm{~m}^{2} \mathrm{~s}^{-3}\right)$ in (a),(c),(e),(g) the EKE budget and (b),(d),(f),(h) the Student's $t$ statistics from 1000 to $150 \mathrm{hPa}$ during the ISV's westerly periods on day 0 averaged for the central Pacific region $\left(5^{\circ}-15^{\circ} \mathrm{N}, 150^{\circ}-170^{\circ} \mathrm{E}\right)$ in the (a),(b) EP-EN, (c),(d) CP-EN, (e),(f) UEN, and (g),(h) NTL years. Two gray lines in (b),(d),(f),(h) indicate the $90 \%$ and $95 \%$ significance levels.

$$
\begin{aligned}
\frac{\partial K^{\prime}}{\partial t}= & \underbrace{-\overline{\mathbf{V}_{h}^{\prime}\left(\mathbf{V}^{\prime} \cdot \nabla\right) \overline{\mathbf{V}}_{h}}}_{\mathrm{KmKe}} \underbrace{-\overline{\mathbf{V}} \cdot \nabla \overline{K^{\prime}}}_{\mathrm{AmKe}} \underbrace{-\overline{\mathbf{V}^{\prime} \cdot \nabla K^{\prime}}}_{\mathrm{AeKe}} \\
& \underbrace{-\frac{R}{p} \overline{\omega^{\prime} T^{\prime}}}_{\text {PeKe }} \underbrace{-\nabla \cdot \overline{\left(\mathbf{V}^{\prime} \Phi^{\prime}\right)}}_{\mathrm{GKe}}+D,
\end{aligned}
$$

where $\mathbf{V}$ is the three-dimensional velocity vector, $\mathbf{V}_{h}$ is the horizontal velocity vector, and $R$ is the gas constant for dry air. The first term on the right-hand side represents the barotropic energy conversion to EKE from mean kinetic energy $(\mathrm{KmKe})$. The second and third terms indicate the advection of EKE by the mean flow $(\mathrm{AmKe})$ and the eddy flow (AeKe), respectively. The fourth term denotes the conversion from eddy available potential energy to EKE through the rising or sinking motion of warm or cold air parcels $(\mathrm{PeKe})$, which is

related to eddy convective activities. The fifth term describes the divergence of the eddy geopotential flux (GKe). The last term $D$ corresponds to the residuals representing subgrid-scale effects or dissipation. Since the terms AmKe, AeKe, and GKe mainly describe the redistribution of energy, they are not considered as real sources or sinks.

Figures 4 and 5 show the area-averaged vertical structures of each composite term in the EKE equation during the EP-EN, CP-EN, UEN, and NTL years in the central Pacific and western North Pacific, respectively. In all panels, the dominant terms are PeKe, KmKe, $\mathrm{GKe}$, and $D$, which is consistent with the results of previous studies relevant to tropical synoptic-scale disturbances (e.g., Lau and Lau 1992; Maloney and Dickinson 2003; ST07b). Large PeKe and the redistribution by GKe were also shown as important terms 

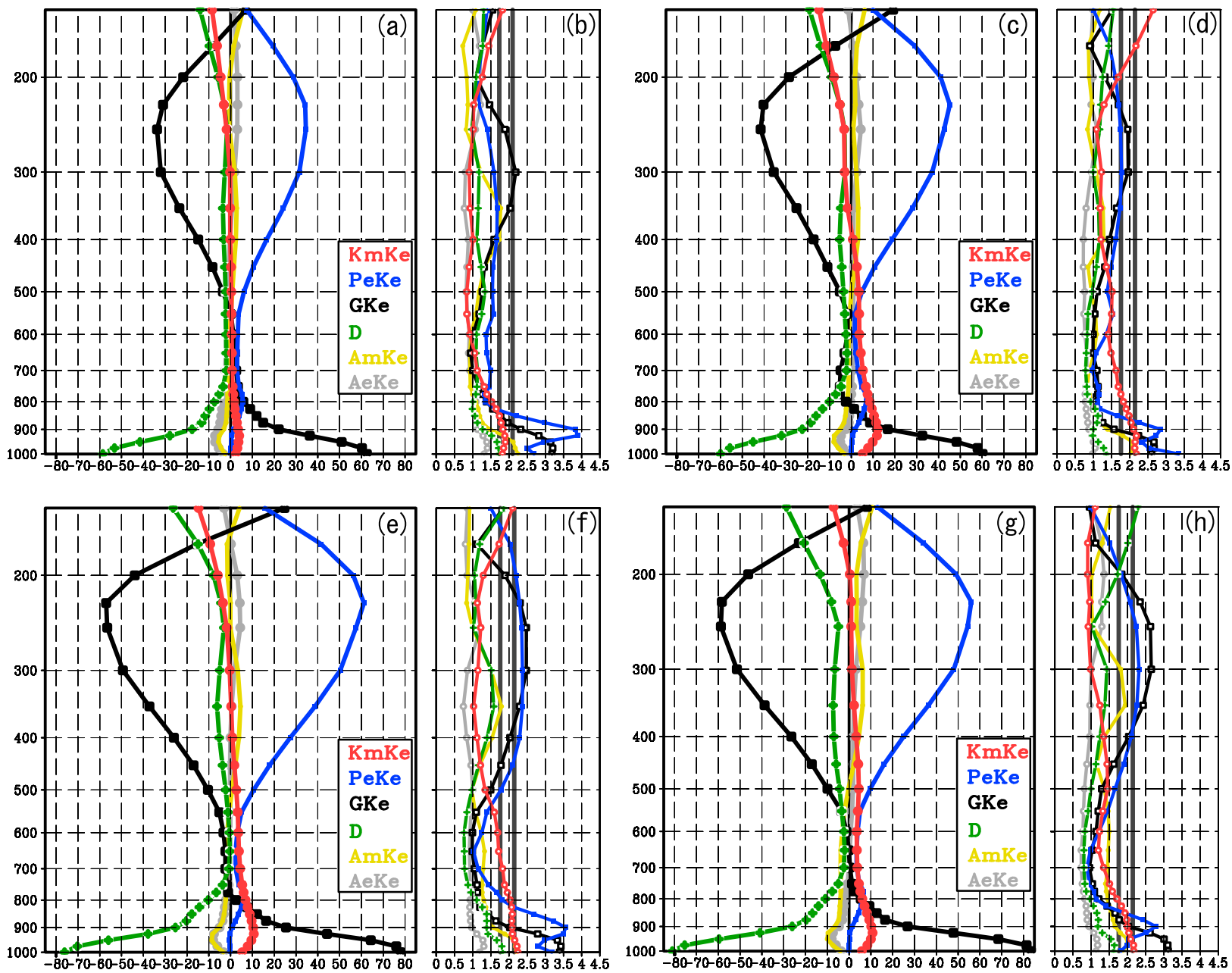

FIG. 5. As in Fig. 4, but for the western North Pacific region $\left(12^{\circ}-22^{\circ} \mathrm{N}, 110^{\circ}-130^{\circ} \mathrm{E}\right)$. Note that ranges of abscissas are approximately 3 times as large as those in Fig. 4.

for the MJO's energy balance (Zhou et al. 2012). In the central Pacific region during the EP-EN years (Figs. 4a,b), significant EKE generations are found in the lower troposphere by $\mathrm{KmKe}$ and in the mid-to-upper troposphere by PeKe. Major contributors to $\mathrm{KmKe}$ are $-\overline{u^{\prime} u^{\prime}} \partial \bar{u} / \partial x$ and $-\overline{u^{\prime} v^{\prime}} \partial \bar{u} / \partial y$ terms (not shown), which represent barotropic wave accumulation through mean zonal wind convergence (e.g., Webster and Chang 1988; Sobel and Bretherton 1999) and energy conversion through meridional shear of mean zonal winds, respectively. These two terms are related to a horizontal distribution of mean zonal winds, which is examined later. The maximum PeKe centered on $250 \mathrm{hPa}$ corresponds to the diabatic heating profile of tropical developed convection. In addition, PeKe in the lower troposphere around $800 \mathrm{hPa}$ depicts energy generation, although its value is smaller than that of $\mathrm{KmKe}$. The EKE is then redistributed from the mid-toupper troposphere centered around $250 \mathrm{hPa}$ to the upper troposphere above $200 \mathrm{hPa}$ and to the boundary layer by GKe. High negative values near the surface found in $D$ indicate strong dissipation in the boundary layer, resulting in a large momentum transfer from the atmosphere to the ocean. In the CP-EN years (Figs. 4c,d), general structures of dominant terms resemble those in EP-EN years, but their values and significance levels are somewhat low. All terms are apparently small during the UEN and NTL years (Figs. 4e-h), representing small EKE generations in the equatorial central Pacific as shown in Fig. 2c. Values of GKe and $D$ in the boundary layer are less than one-quarter of those in EP-EN years, indicating that atmospheric forcing to the ocean is very weak. Figure 5 shows the same vertical structures as those in Fig. 4, but these are averaged for the western North Pacific. Contrary to Fig. 4, the dominant four terms are greater in the UEN and NTL years (Figs. 5e-h) and less in the EP-EN years (Figs. 5a,b). $\mathrm{PeKe}$ and $\mathrm{GKe}$ in the upper troposphere in the CP-EN 

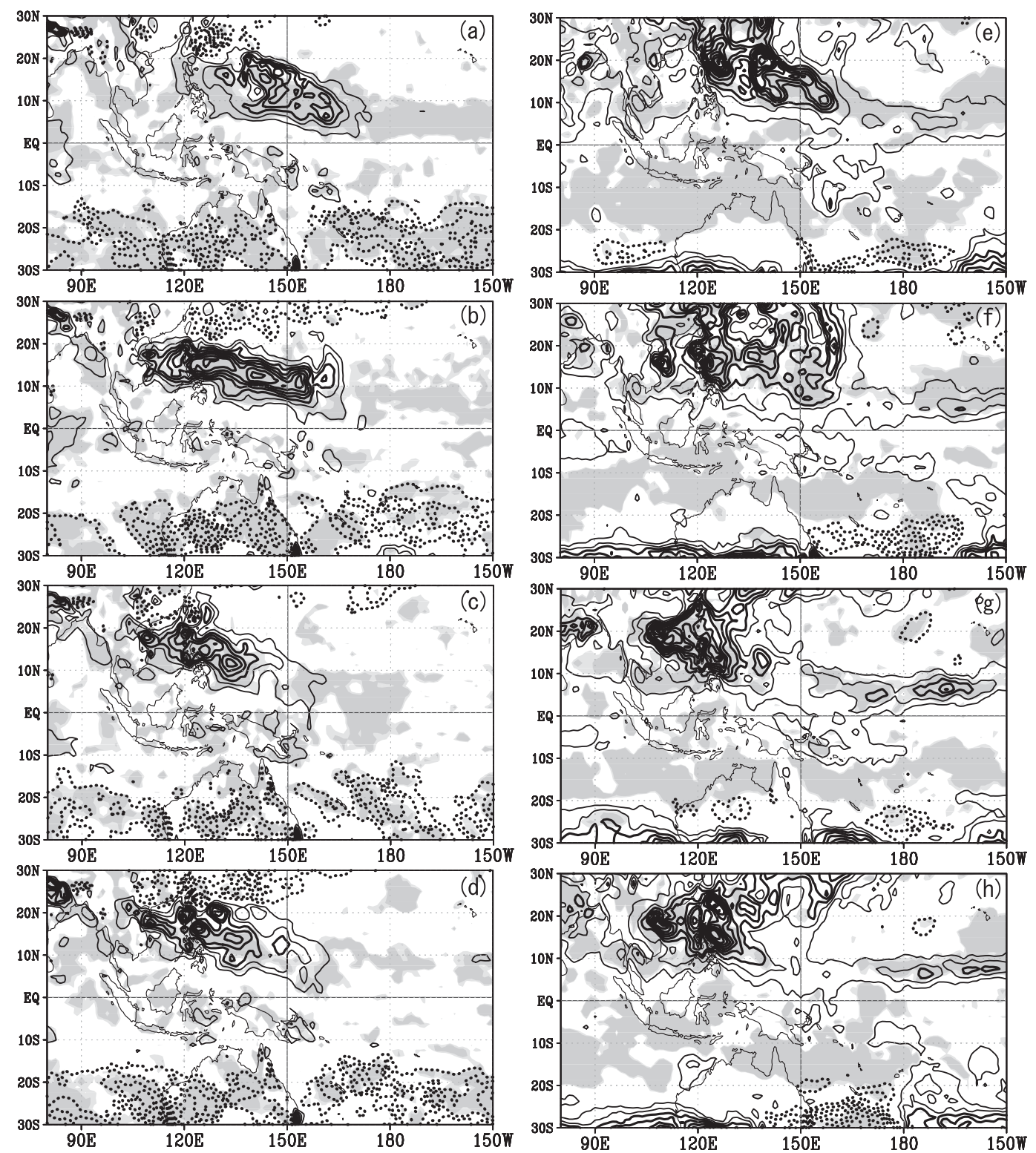

FIG. 6. Composites of (a)-(d) the barotropic energy conversion term at $850 \mathrm{hPa}$ and (e)-(h) the conversion from the available potential energy term at $250 \mathrm{hPa}$ based on the ISV's westerly periods in the (a),(e) EP-EN, (b),(f) CPEN, (c),(g) UEN, and (d),(h) NTL years. Solid contours represent positive values, and zero contours are omitted. Contour interval is $3.0(10.0) \times 10^{-5} \mathrm{~m}^{2} \mathrm{~s}^{-3}$ in the barotropic energy conversion (available potential energy) term, and thick solid contours indicate at and above $9.0(30.0) \times 10^{-5} \mathrm{~m}^{2} \mathrm{~s}^{-3}$. Dark (light) shading indicates more than 95\% (90\%) significance level.

years (Fig. 5 c) have intermediate values between those present in the EP-EN and UEN/NTL years, whereas KmKe values correspond to those in the UEN/NTL years, indicating that the CP-EN years have somewhat mixed features of the EP-EN and UEN/NTL years, especially over the western North Pacific region. Note that the ranges of PeKe, GKe, and $D$ in Fig. 5 are 3 times greater than those in Fig. 4, whereas KmKe ranges in Figs. 4 and 5 are similar. This may be because atmospheric convection is more active climatologically in the western North Pacific than in the equatorial central Pacific especially in the focused season.

Horizontal structures of two dominant energy sources, $\mathrm{KmKe}$ at $850 \mathrm{hPa}$ and $\mathrm{PeKe}$ at $250 \mathrm{hPa}$, are shown in Fig. 6 . The positive $\mathrm{KmKe}$ and PeKe maximized in a southeast-northwest band from north of Philippines to the equatorial central Pacific in the EP-EN and CP-EN years (Figs. 6a,b,e,f) generally agree with the distributions 
of high EKE (Fig. 2), although a large PeKe extends more meridionally compared to KmKe. During the UEN and NTL years (Figs. 6c,d,g,h), high KmKe and PeKe values are located over the western North Pacific. The South China Sea has strongly enhanced KmKe and PeKe in the CP-EN, UEN, and NTL years, whereas these are very weak in the EP-EN years. These differences in the distributions are associated with the mean wind fields, which are explained later. In summary, the horizontal and vertical structures of the dominant terms in the EKE budget (Figs. 4-6) show substantial differences in their distribution when comparing between the EP-EN and UEN/NTL years. However, the distributions of the dominant terms during the CP-EN years are similar to those in the EPEN years over the equatorial central Pacific and those in the UEN/NTL years over the South China Sea, representing the mixed characteristics of the EP-EN and UEN/NTL years. In addition, the overall similarity in the distributions of EKE and the dominant terms is found between the UEN and NTL years, although their SST anomaly and SLA patterns are different, which is examined in the next section.

The two main contributors to $\mathrm{KmKe}$, the barotropic wave accumulation and the conversion through meridional shear of mean zonal winds, are related to the horizontal distribution of mean zonal winds. Figure 7 shows composite mean zonal winds at $850 \mathrm{hPa}$. In all years, the mean westerly winds centered near $10^{\circ} \mathrm{N}$ spread from the Indian Ocean to the western Pacific in general, representing the ISV's westerly periods and the seasonal wind pattern for the April-September period focused on in this study. Notable is that the mean westerlies penetrate the equatorial central Pacific in the EP-EN and CP-EN years but are confined over the western Pacific in the UEN and NTL years. As a result, the zonal convergence and meridional shear of mean zonal winds are enhanced around the equatorial central Pacific in the EP-EN and CP-EN years, leading to large $\mathrm{KmKe}$ values in this region. Over the South China Sea, enhanced westerlies around $10^{\circ} \mathrm{N}$ and easterlies around $20^{\circ} \mathrm{N}$ intensify the meridional shear of mean zonal winds, resulting in higher $\mathrm{KmKe}$ in the CP-EN, UEN, and NTL years, even though the significance levels of the easterlies in the CP-EN years are low.

\section{Background states in the EP-EN, CP-EN, and UEN years}

Mean zonal winds shown in Fig. 7 represent a combination of intraseasonal, seasonal, and interannual variability. In this section, the background states that represent seasonal and interannual time scales are
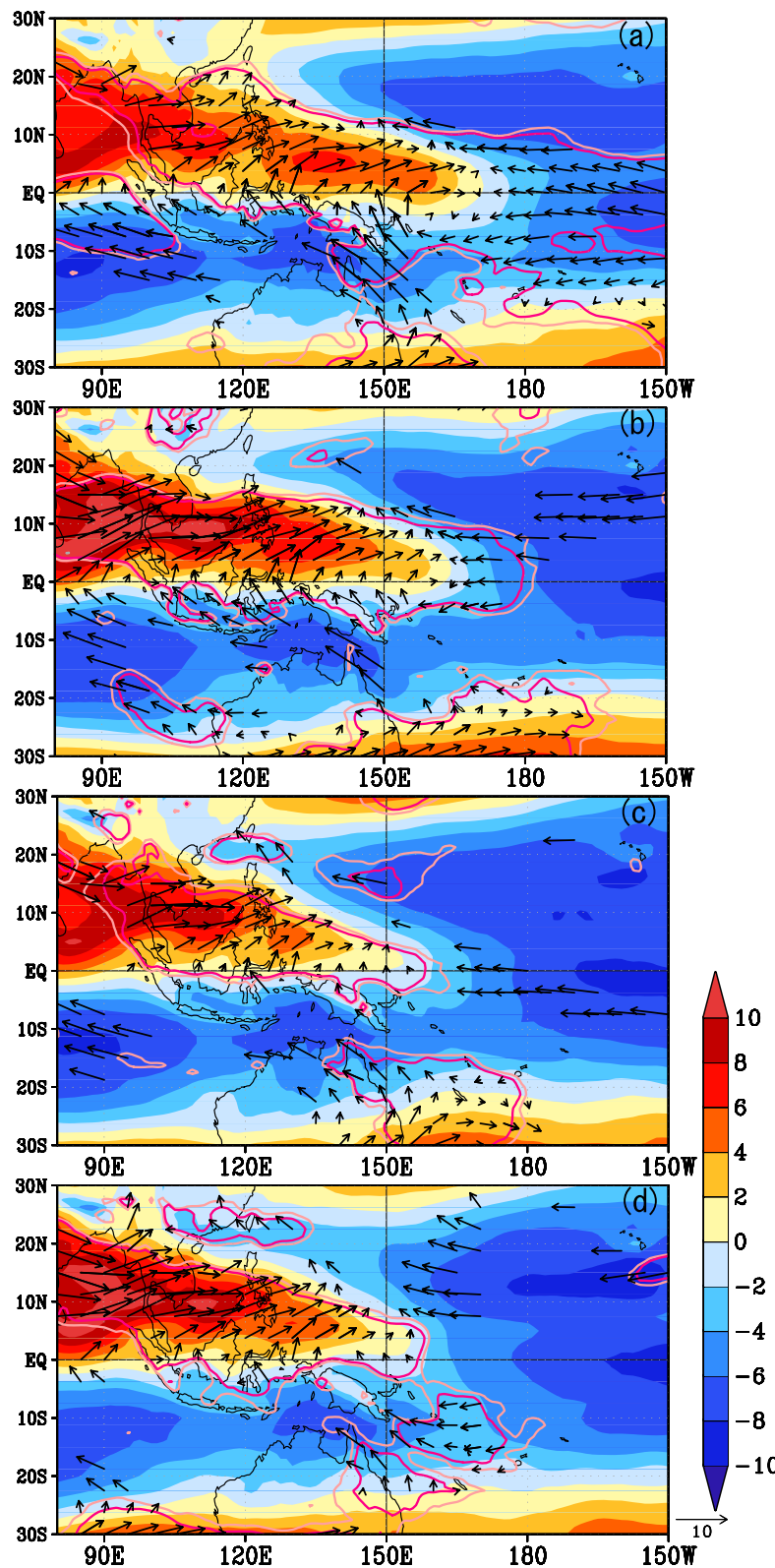

FIG. 7. Composite mean zonal winds at $850 \mathrm{hPa}\left(\mathrm{m} \mathrm{s}^{-1}\right)$ defined as the 11-day running mean based on the ISV's westerly periods in the (a) EP-EN, (b) CP-EN, (c) UEN, and (d) NTL years. Magenta (pink) contours represent the $95 \%$ (90\%) significance level for the zonal components. Vectors indicate the composite environmental wind fields, where either the zonal or the meridional component is significant at the $95 \%$ level.

focused on. Figure 8 shows seasonal mean zonal winds averaged for April-June (AMJ) and July-September (JAS) during the EP-EN, CP-EN, UEN, and NTL years. As a seasonal evolution of the Indian/Asian summer monsoon, weak westerly winds occur on and north of the equator over the western Pacific in AMJ and intensify eastward in JAS in all four types of years. Similar to 

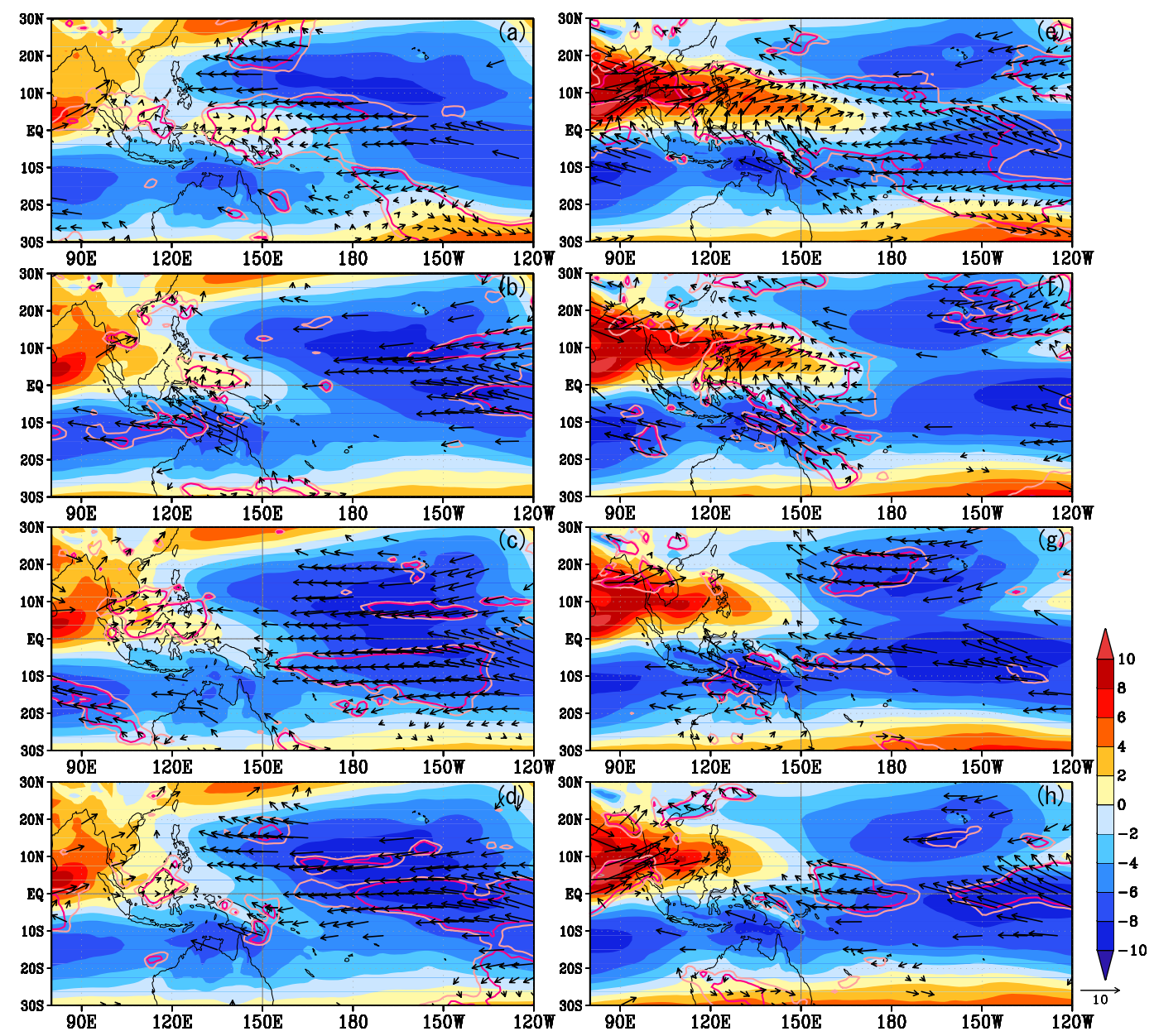

FIG. 8. Seasonal mean zonal winds at $850 \mathrm{hPa}\left(\mathrm{m} \mathrm{s}^{-1}\right.$ ) for (a)-(d) AMJ and (e)-(h) JAS in the (a),(e) EP-EN, (b),(f) CP-EN, (c),(g) UEN, and (d),(h) NTL years. Magenta (pink) contours represent the $95 \%(90 \%)$ significance level for the zonal components. Vectors indicate the composite seasonal mean wind fields where either the zonal or the meridional component is significant at the $95 \%$ level.

Fig. 7, the westerlies retract to the west (AMJ) or northwest (JAS) in the UEN and NTL years (Figs. 8c,d,g,h) compared to the EP-EN and CP-EN years. In addition, the westerlies extend farther east in both AMS and JAS during the EP-EN years compared to the CP-EN years (Figs. 8a,b,e,f). These results indicate that the interannual variability of zonal winds over the western and central Pacific contributes significantly to the mean wind states shown in Fig. 7, which determine the region of large KmKe. The similarity between composite mean wind fields of Fig. 7 and seasonal mean wind fields of Figs. 8e-h averaged for JAS may raise concerns about a seasonal bias in ISV events. The numbers of ISV events detected in AMJ and JAS are 31 and 29, respectively, indicating that there is no seasonal bias in the ISV events.

Another energy source found in the EKE budget is $\mathrm{PeKe}$, which is related to eddy convective activities. Figure 9 shows seasonal mean SST anomalies averaged for AMJ and JAS. A clear dipole pattern exists, with the western North Pacific cooling and the central Pacific warming in AMJ during the EP-EN years (Fig. 9a), whereas a widespread warming occurs in the western and central Pacific in both equatorial and off-equatorial regions during the CP-EN years (Fig. 9b). During the UEN years (Fig. 9c), the western Pacific warming maximizes in the off-equatorial region around $10^{\circ}-20^{\circ} \mathrm{N}$, and cooling occurs in the central South Pacific. Whereas the widespread western Pacific warming extend to the equatorial region during the UEN years, the equatorial cooling dominates except around the Maritime Continent during the NTL years (Fig. 9d). During the EP-EN and CP-EN years, the anomalous warming in the central Pacific, where SST is climatologically cooler than the western Pacific, facilitates anomalous active convection over the region. It is related to the eastward-extended PeKe shown in Figs. 6e-g. In addition, the warming in 

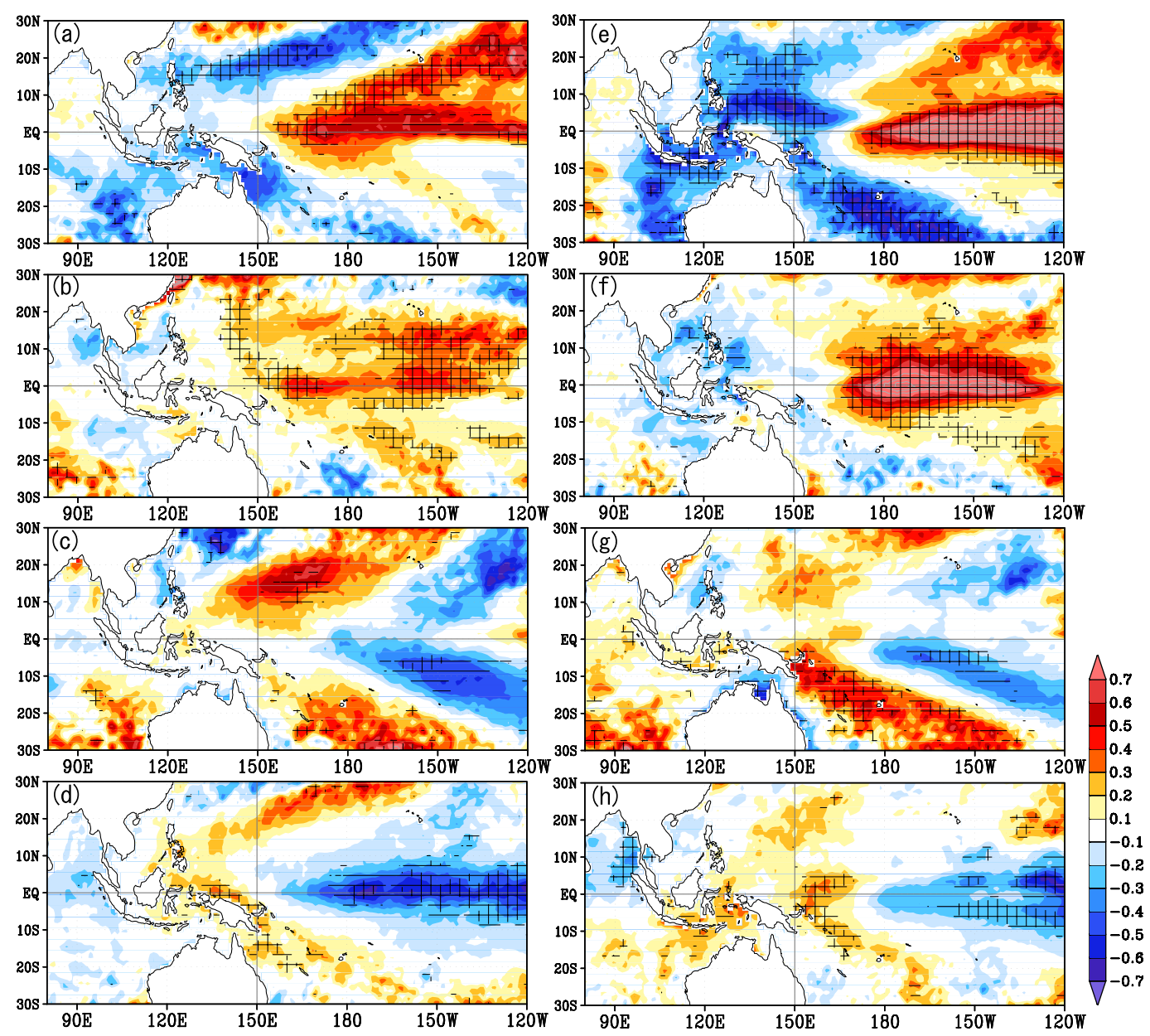

FIG. 9. Seasonal mean SST anomalies $\left({ }^{\circ} \mathrm{C}\right)$ for (a)-(d) AMJ and (e)-(h) JAS in the (a),(e) EP-EN, (b),(f) CP-EN, (c), (g) UEN, and (d),(h) NTL years. Cross (single) hatching represents more than $95 \%(90 \%)$ significance level.

the equatorial central Pacific during the EP-EN and CPEN years showing the eastward extent of the warm pool edge allows the anomalous westerlies to intensify or extend eastward. These westerlies can enhance $\mathrm{KmKe}$ as mentioned in Figs. 7 and 8. The equatorial warming strengthens in JAS and reaches a maximum in the eastern and central Pacific during the EP-EN and CPEN years, respectively (Figs. 9e,f), indicating the onset of El Niño in JAS. During the UEN years (Fig. 9g), the signals of SST anomalies in the western North Pacific and the central South Pacific weaken in JAS, whereas the warming around $160^{\circ} \mathrm{E}$ south of the equator is enhanced. Contrary to the EP-EN and CP-EN years, there is no El Niño pattern found in the anomalous SST distribution during the UEN years.

Whereas SST is an important background state for the ocean-atmosphere interaction, the $\mathrm{OHC}$ buildup is known as a necessary condition for El Niño development. The UEN years in this study are defined as non-El Niño years with high-OHC buildup early in the year, as explained in section 2. Figure 10 shows seasonal mean SLA, the index of OHC, for AMJ and JAS. Although the spatial patterns of SLA and SST anomalies in the tropics are similar if the ocean above the thermocline has a barotropic structure, they are different in some cases where surface heat flux, horizontal advection in the upper ocean, or local upwelling dominates. A strong resemblance between the spatial patterns of SST anomalies and SLA for JAS in the EP-EN years (Figs. 9e and 10e) indicates that the buildup of warm water in the upper ocean determines distributions of both SST anomalies and SLA. In AMJ, however, anomalous cooling in SLA found in the western Pacific is located at a lower latitude between the equator and $10^{\circ} \mathrm{N}$ compared to SST cooling between $10^{\circ}$ and $20^{\circ} \mathrm{N}$ (Figs. 9a and 10a). This discrepancy may be caused by the upwelling of cold water induced by wind stress curl related to a cyclonic wind anomaly field in the western North Pacific (Fig. 11a). In the CP-EN years, the SLA pattern differs vastly from the SST anomalies in AMJ 

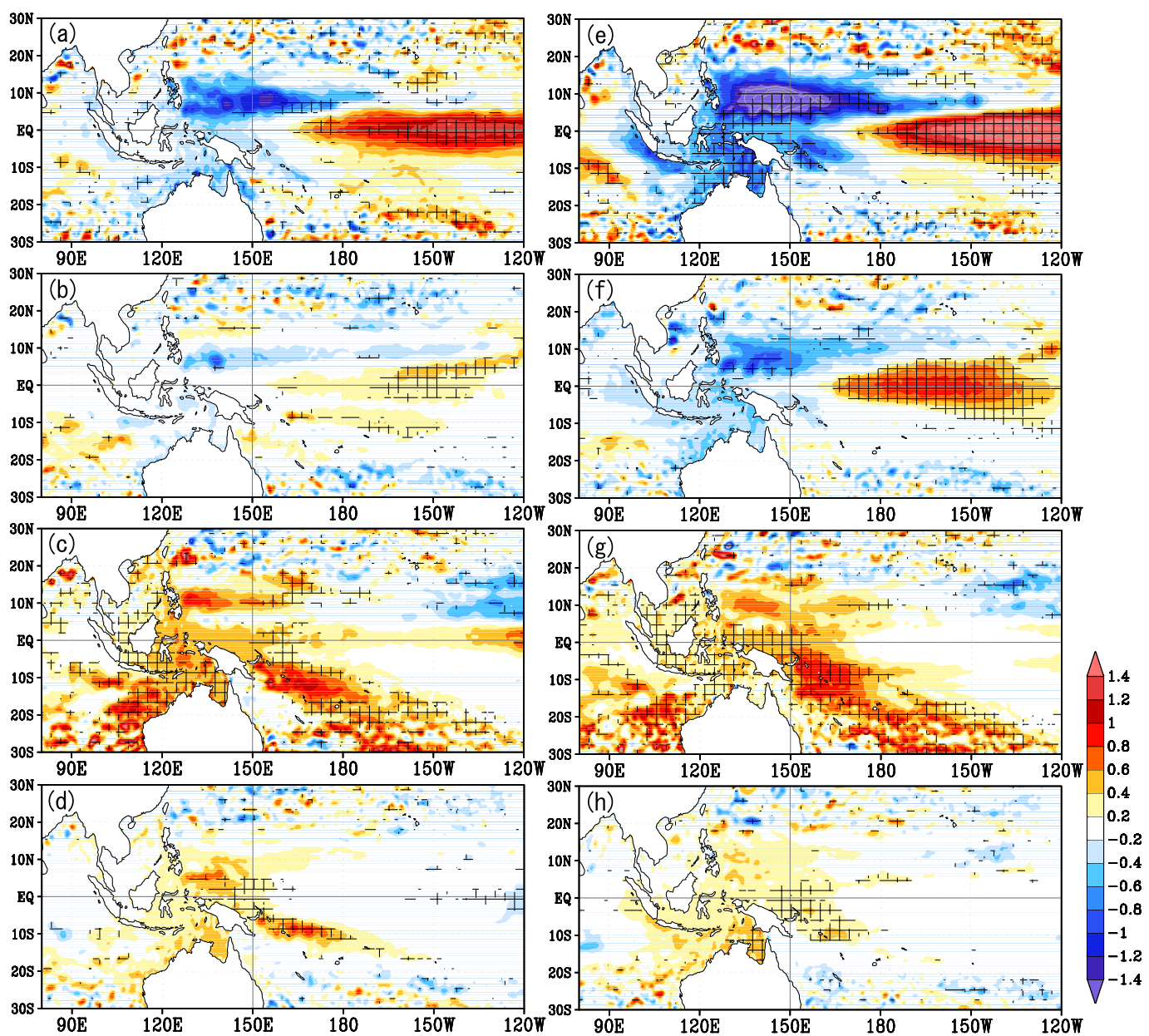

FIG. 10. As in Fig. 9, but for seasonal mean SLA (cm).

(Figs. 9b and 10b), but they are relatively similar in JAS (Figs. 9f and 10f). Focusing on the AMJ, positive SLA values are confined around the equator, and negative SLA values occur in an off-equatorial area. This is in contrast to the widespread warming in SST anomalies that may be induced by widespread westerly wind anomalies (Fig. 11b) in the background easterly winds, which leads to less evaporative cooling. The SLA patterns in the EP-EN and CP-EN years are similar albeit at different amplitudes, whereas the UEN years have a distinct pattern that is different to the other two types of El Niño years (Figs. 10c,g). These SLA patterns in the UEN years show an $\mathrm{OHC}$ buildup around the equator and in the off-equatorial western Pacific centered on $10^{\circ} \mathrm{N}$. This stronger warming found both in SST anomalies and SLA in the off-equatorial area may induce a large PeKe over the region because the SST warming enhances convective activities and positive SLA is often a persistent energy source for synoptic convection. In addition, it is interesting to note that significant cooling in the central South Pacific found in SST disappears in SLA, indicating that the SST cooling is generated by the upper-ocean process. If wind anomaly fields and sea level pressure anomalies are considered (Figs. 11c,g), this SST phenomenon may be caused by surface heat flux thorough strong southeasterly winds blowing from a subtropical high located in the southeastern Pacific. Thus, the discrepancy between the distributions of SLA and SST anomalies found in the CP-EN and UEN years indicate that the upper-ocean processes are important for the development of the atmospheric eddies through the SST distributions. During the NTL years, the overall signals of SLA are very weak, although weak warming is found in the western Pacific (Figs. 10d,h).

As shown partly in previous paragraphs, wind anomalies can interact with anomalous SST distributions and are related to surface pressure anomaly patterns. Figure 11a shows the high pressure region west of $150^{\circ} \mathrm{E}$ and the low pressure region east of this longitude during AMJ in the EP-EN years (Fig. 11a). This roughly corresponds to the SST anomaly patterns (Fig. 9a). 

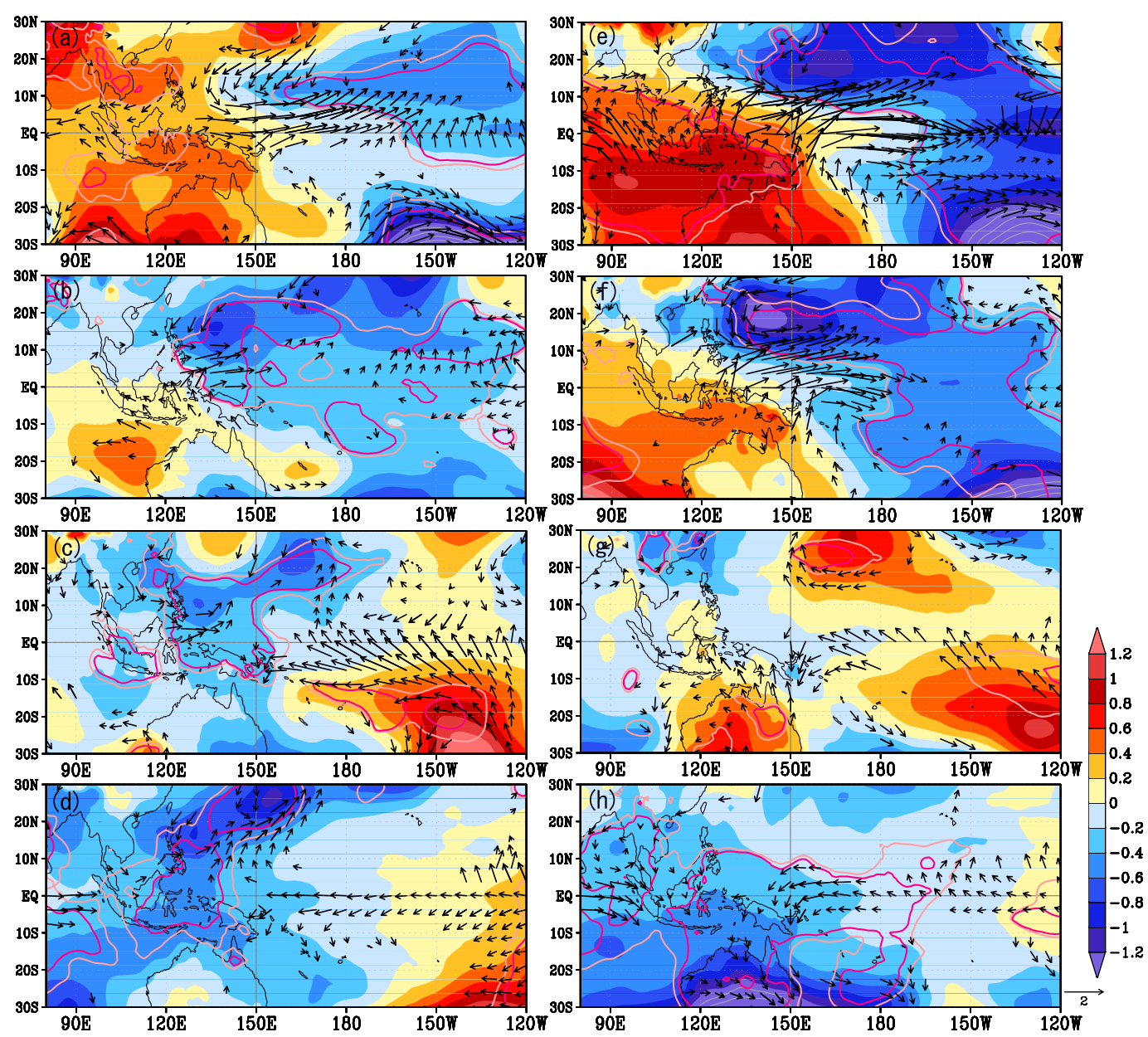

FIG. 11. Seasonal mean sea level pressure anomalies (hPa) for (a)-(d) AMJ and (e)-(h) JAS in the (a),(e) EP-EN, (b),(f) CP-EN, (c),(g) UEN, and (d),(h) NTL years. Magenta (pink) contours represent the $95 \%$ (90\%) significance level. Vectors indicate the seasonal mean wind anomaly fields at $850 \mathrm{hPa}\left(\mathrm{m} \mathrm{s}^{-1}\right)$, where either the zonal or the meridional component is significant at the $95 \%$ level.

Conversely, AMJ distributions in the CP-EN, UEN, and NTL years show significant low pressure anomalies in the western North Pacific (Figs. 11b-d), which represent large-scale ascending motion and facilitate active synoptic convection, leading to a large PeKe over the region. This pressure pattern is related with the off-equatorial SST warming in the western Pacific. The CP-EN years, in particular, show low pressure anomalies extending from the western Pacific to the central Pacific, which is reflected by the widespread SST warming from $20^{\circ} \mathrm{N}$ to $20^{\circ} \mathrm{S}$ centered in the equatorial central Pacific. Thus, the background SST distributions in the off-equatorial region interact with pressure and wind patterns and may determine the regions of active eddy convection. As for JAS, equatorial westerlies and off-equatorial low pressure systems develop in association with the central Pacific SST warming, representing El Niño development in the EP-EN and CP-EN years
(Figs. 11e,f). In the UEN and NTL years (Figs. 11g,h), pressure anomalies weaken and easterlies dominates around the equator in JAS, indicating that El Niño grows stagnant.

These results show that positive peaks in SST anomalies and SLA and lower pressure patterns found in the off-equatorial region during the UEN years can construct preferable conditions for active eddy disturbances there and can result in the reduction of equatorial eddies such as WWBs even though the weak warming occurs in the equatorial western Pacific. Note that the mechanism generating the southeastern Pacific high and outflows of southeasterlies into the equatorial region that occur during the UEN years needs further investigation because the southeasterlies have been considered as an inhibiting factor of the development of $2014 \mathrm{El} \mathrm{Niño}$ (Min et al. 2015; Maeda et al. 2016). A comparison of the UEN and NTL years indicates that there are discrepancies in SST anomalies and SLA, although horizontal 


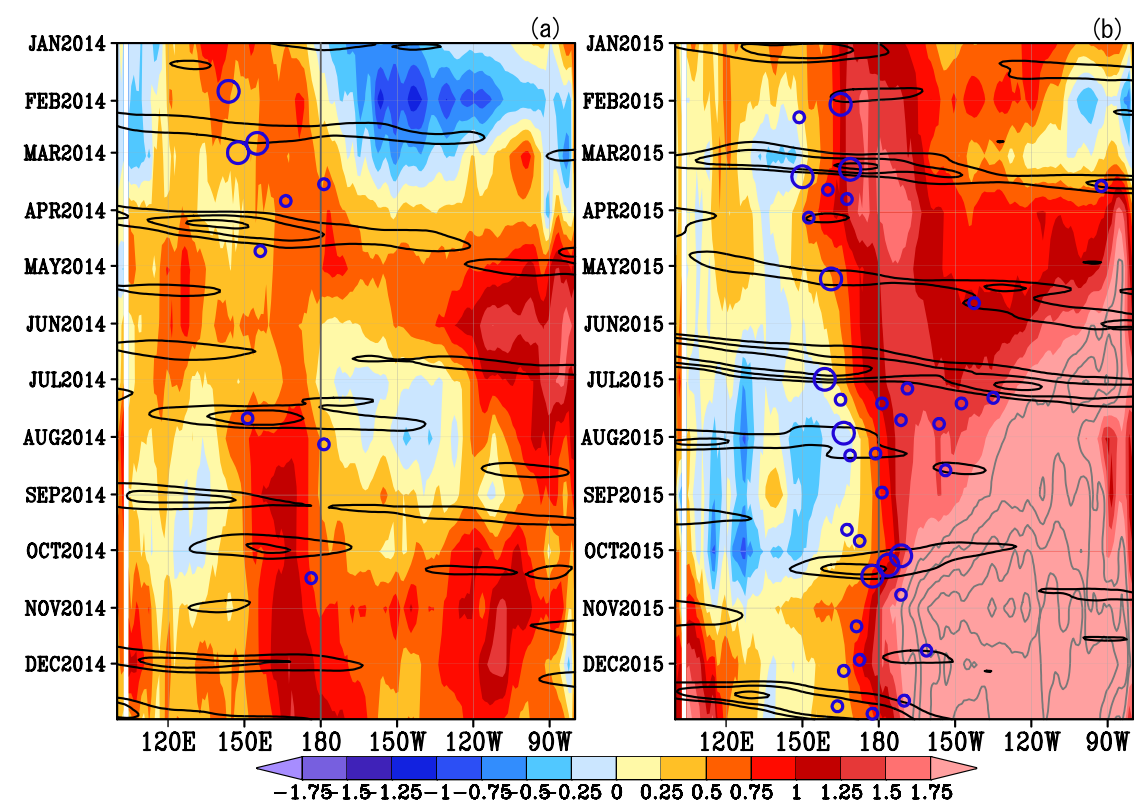

FIG. 12. Time-longitude sections of monthly SST anomalies $\left({ }^{\circ} \mathrm{C}\right.$; shading) averaged between $5^{\circ} \mathrm{N}$ and $5^{\circ} \mathrm{S}$ for (a) 2014 and (b) 2015. Contours represent negative BPF velocity potential at $200 \mathrm{hPa}$ averaged between $10^{\circ} \mathrm{N}$ and $10^{\circ} \mathrm{S}$ with intervals of $0.32 \times 10^{7} \mathrm{~m}^{2} \mathrm{~s}^{-1}$ corresponding to one standard deviation for the BPF velocity potential averaged over the western Pacific (see section $2 \mathrm{c}$ for details). Circles indicate the days and longitudes of maximum anomalies of WWBs, with larger ones representing strong WWBs with anomalies over twice the threshold.

distributions in wind and pressure fields are similar. The UEN years show the weak warming in the equatorial western Pacific, which leads to more preferable condition for equatorial eddies compared to the NTL years that have the equatorial cooling. However, strong warming in the off-equatorial region can overcome the effect of the weak equatorial warming in the UEN years, and the discrepancies between the UEN and NTL years become less apparent.

\section{Case analysis of the 2014 UEN and 2015 EP-EN events}

Unexpected developments of El Niño observed during 2014 and 2015 have received wide attention as mentioned in the introduction. In this section, these two events are investigated in terms of the EKE distribution and background states. Figure 12 shows equatorial SST anomalies, ISV events, and WWB occurrences in the 2014 UEN and 2015 EP-EN years. Several ISV events are observed both in 2014 and 2015, whereas WWB frequencies show distinct statistical differences between the two years as revealed in section 2 (Tables 1 and 2). Strong WWB forcing during the ISV convection in the western Pacific in February 2014 induces the eastern Pacific warming in boreal spring. However, this warming decays with a scarcity of WWB occurrences after April. Contrary to 2014, ISV events in 2015 are constantly accompanied by several WWB occurrences, and positive SST anomalies in the eastern Pacific continue to develop until the end of the year, finally becoming strong El Niño. Composite EKE values based on the ISV's westerly periods from April to September (Fig. 13) show that in 2015, large EKE values extend farther east compared with those in 2014 and reach the equatorial central Pacific. Note that significance levels shown in Fig. 13 are lower than those of composites for the whole period (Fig. 2) because the number of ISV events for composites from April to September is very small (i.e., four and three in 2014 and 2015, respectively). Despite a small number of composite events, EKE values in the equatorial central Pacific in 2015 exceed the $95 \%$ significance level, indicating that most of ISV events bear WWB occurrences. Composite results of the two dominant terms in the EKE equation, $\mathrm{KmKe}$ and $\mathrm{PeKe}$, are shown in Fig. 14. The spatial patterns of KmKe show an apparent discrepancy between 2014 and 2015. The positive $\mathrm{KmKe}$ maximizes in the western North Pacific and the equatorial central Pacific in 2014 and 2015, respectively, which is similar to the discrepancy between the EP-EN and UEN years (Figs. 6a,c). As for PeKe, large values are located in the western North Pacific both in 2014 and 


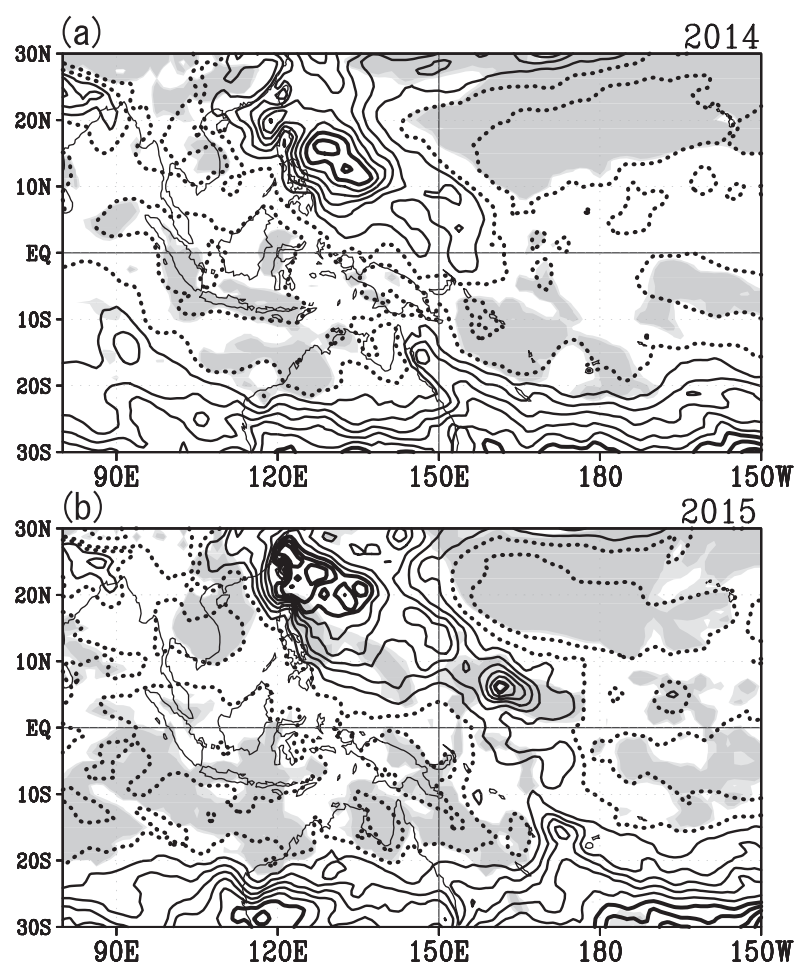

FIG. 13. As in Fig. 2, but for the cases of (a) 2014 and (b) 2015 with contour intervals of $3.0 \mathrm{~m}^{2} \mathrm{~s}^{-2}$. Thin (thick) solid contours represent EKE values at and above $9.0(24.0) \mathrm{m}^{2} \mathrm{~s}^{-2}$.

2015, but they extend westward and southeastward in 2014 and 2015, respectively. These results indicate that synoptic eddies preferably develop in the western North Pacific and the equatorial central Pacific in 2014 and 2015, respectively. Basic states influencing the KmKe and PeKe are shown by seasonal mean SST anomalies and wind anomaly fields for AMJ and JAS in 2014 and 2015 (Fig. 15). Both SST and wind anomaly patterns in 2015 (Figs. 15b,d) generally correspond to those in the EP-EN years (Figs. 9a,d and 11a,d), consisting of strong equatorial westerly anomalies and anomalous warming (cooling) centered in the equatorial central Pacific (the western North Pacific), although an off-equatorial warming east of $180^{\circ}$ in JAS is larger in 2015 than the all EP-EN years. In AMJ 2014 (Fig. 15a), the widespread SST warming is similar to that in the CP-EN years (Fig. 9b), but a positive SST anomaly peak located in the off-equatorial western Pacific resembles that in the UEN years (Fig. 9c). Compared to 2015, westerly wind anomalies around the equator in 2014 are confined in the western Pacific, indicating that a favorable region for large $\mathrm{KmKe}$ is also confined in the region. In addition, there are strong southeasterly wind anomalies blowing into the equatorial central Pacific that are also found in the composites for the UEN years (Fig. 11c). In JAS 2014 (Fig. 15c), equatorial SST anomalies east of $180^{\circ}$ decrease, resulting in stagnation of El Niño growth, whereas the western Pacific warming extends northward. Previous studies indicated that the inhibiting factors of the 2014 El Niño are the lack of WWBs after boreal spring (Menkes et al. 2014) and anomalous southeasterly wind blowing into the equator in boreal summer (Min et al. 2015; Maeda et al. 2016). It is suggested in this study that an off-equatorial peak in SST anomalies and westward-retreated westerly basic states confine eddy activities to the western North Pacific and explain the lack of WWBs near the equator after boreal spring.

\section{Summary and discussion}

In this study, we examine where synoptic disturbances such as WWBs prefer to develop when ISV convection is activated in the western and central Pacific during boreal spring and summer (April-September), focusing on the relationship with interannual variability such as ENSO. This is done by comparing the EP-EN, CP-EN, UEN, and NTL years using the EKE budget analysis based on the ISV's westerly periods. Synoptic eddies develop strongly in the equatorial central Pacific, the western North Pacific, and in both regions during the EP-EN, UEN/NTL, and CP-EN years, respectively. The dominant terms in the EKE budget are as follows: the two energy generation terms (KmKe in the lower troposphere and PeKe in the upper troposphere), the redistribution term into the upper and boundary layers $(\mathrm{GKe})$, and the strong dissipation term in the boundary layer $(D)$. These dominant terms are consistent with those in the previous studies regarding tropical synopticscale disturbances (e.g., Lau and Lau 1992; Maloney and Dickinson 2003; ST07b). Eddy disturbances are predominantly developed by mean zonal wind gradients in the lower troposphere and by SST distributions, which can enhance KmKe and PeKe, respectively. During the EP-EN and CP-EN years, mean westerly winds centered on $10^{\circ} \mathrm{N}$ penetrate the equatorial central Pacific, resulting in large $\mathrm{KmKe}$ in the region through strong zonal wind convergence. The equatorial central Pacific warming also facilitates active convection, leading to a large PeKe. When eddies develop around the equator, they can generate WWBs close to the equator, which influences the development of El Niño through zonal advection of warm surface water and excitation of the oceanic downwelling Kelvin waves as indicated in previous studies (e.g., McPhaden and Taft 1988; Kessler et al. 1995; Lengaigne et al. 2002). During the UEN years, however, the mean westerlies are retracted westward, and SST warming is centered in the offequatorial region, leading to active eddies in the offequatorial region. Because the oceanic radius of 

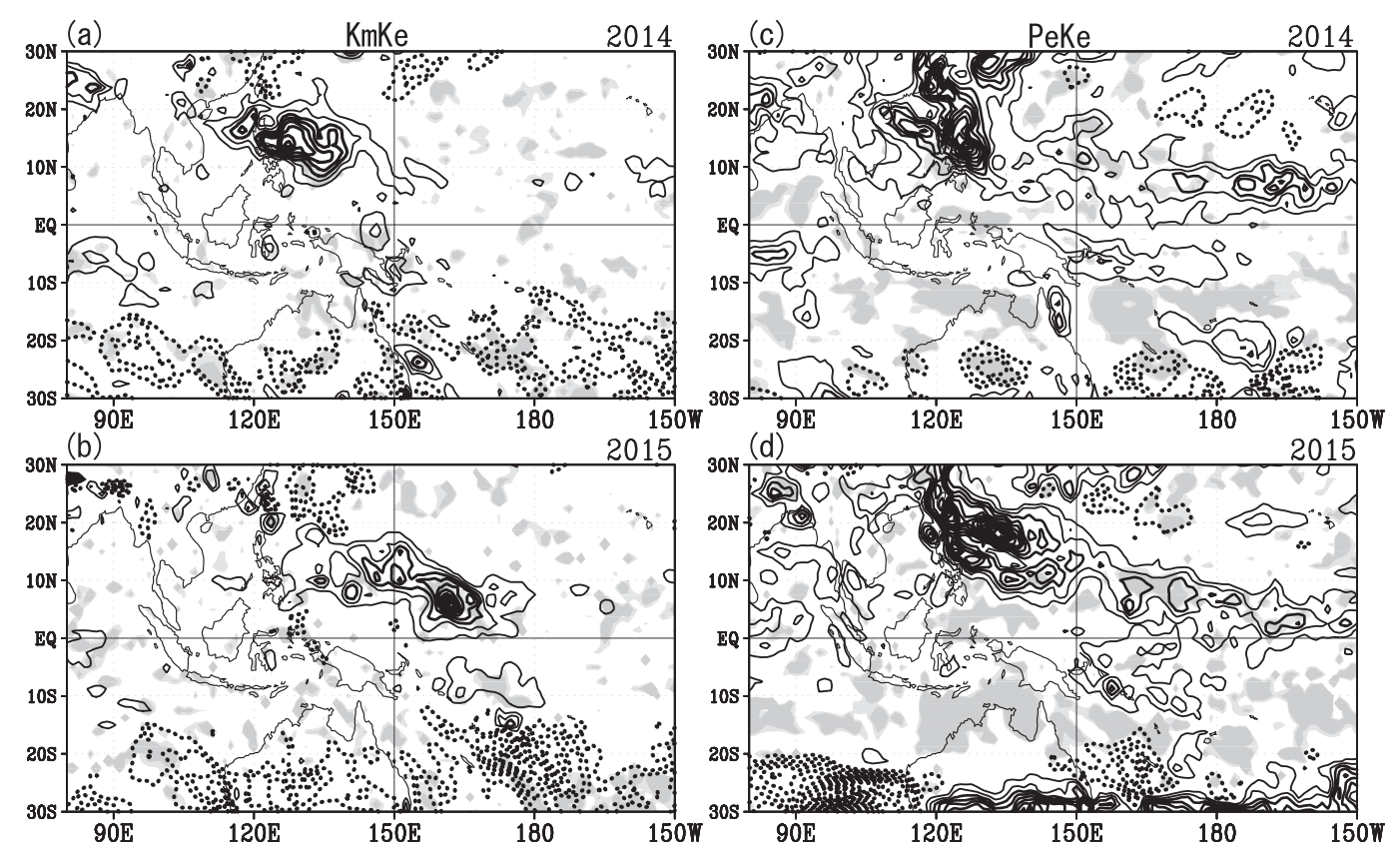

FIG. 14. As in Fig. 6, but for the cases of (a),(c) 2014 and (b),(d) 2015 . Contour interval is $4.0(12.0) \times 10^{-5} \mathrm{~m}^{2} \mathrm{~s}^{-3}$ in the barotropic energy conversion (available potential energy) term, and thin (thick) solid contours indicate at and above $12.0(36.0) \times 10^{-5} \mathrm{~m}^{2} \mathrm{~s}^{-3}$.

deformation is narrower than the atmospheric one, the off-equatorial eddies can neither excite the oceanic Kelvin waves nor exert an influence on El Niño. Even though the $\mathrm{OHC}$ buildup near the equator is found in the UEN years, the EKE values near the equator are small, and their distributions are similar to those in the
NTL years. Strong warming in the off-equatorial region may make the equatorial warming less effective during the UEN years. The differences in the EKE distributions between EP-EN/CP-EN and UEN/NTL years are generally consistent with the results in ST07b, although eddies in the western North Pacific (the central South
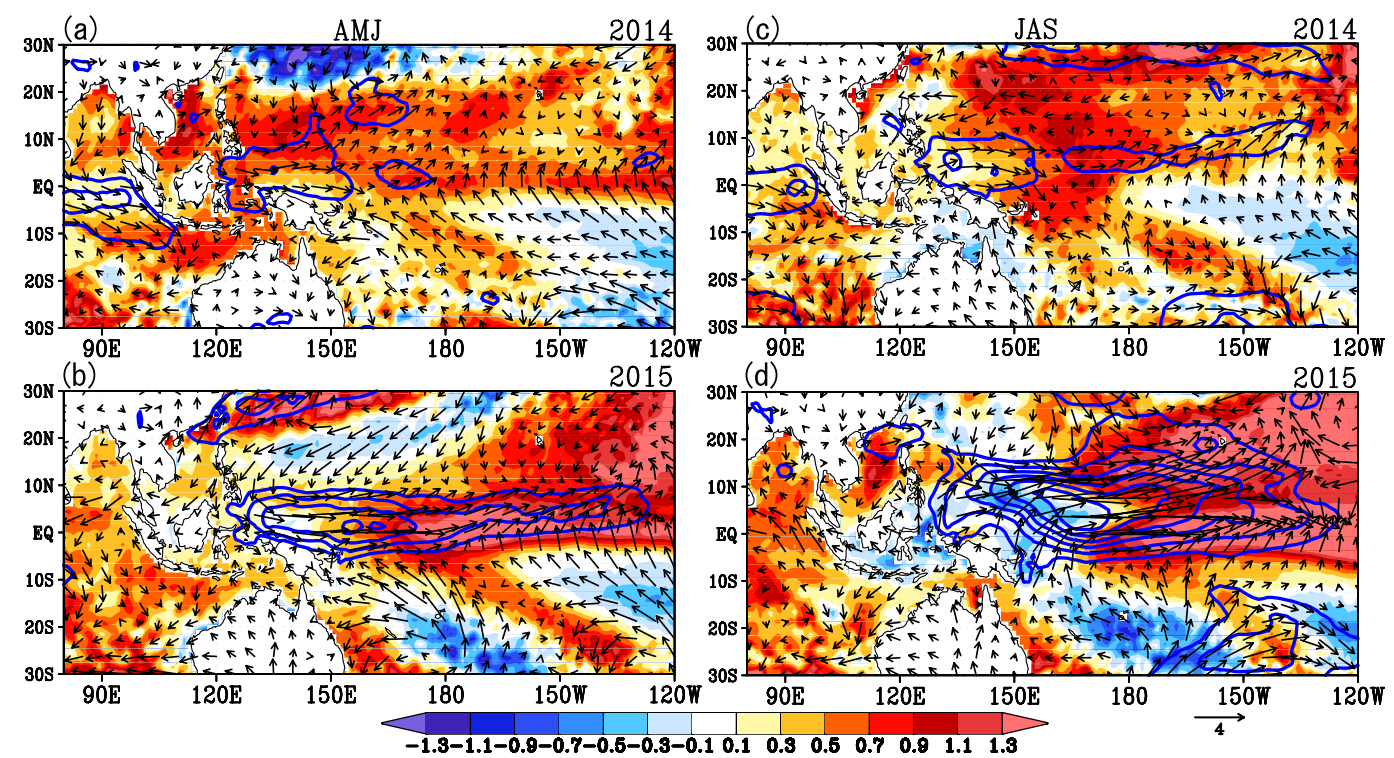

FIG. 15. Seasonal mean SST anomalies $\left({ }^{\circ} \mathrm{C}\right)$ for (a),(b) AMJ and (c),(d) JAS in (a),(c) 2014 and (b),(d) 2015. Vectors represent the seasonal mean wind anomaly fields at $850 \mathrm{hPa}\left(\mathrm{m} \mathrm{s}^{-1}\right)$. Contours indicate positive zonal wind anomalies with intervals of $1.0 \mathrm{~m} \mathrm{~s}^{-1}$, and zero contours are omitted. 
Pacific) are relatively suppressed (enhanced) in ST07b because they focused on all seasons including boreal winter when the ISV is the most active and used different datasets. In addition, ST07b did not take the OHC buildup and two types of El Niño into account.

The absence of WWBs and small EKE values near the equator found in the UEN years reconfirm the importance of the high-frequency atmospheric forcing for the El Niño development. Moreover, frequent WWB occurrences when the tropical Pacific warm pool is extended eastward observed in the EP-EN and CP-EN years indicate the modulation of WWB occurrences by warm pool displacements, which is called the state-dependent noise (e.g., Eisenman et al. 2005; Gebbie et al. 2007; Kug et al. 2008). A previous modeling study (Fedorov et al. 2015) shows that the presence (absence) of WWBs leads to EP-EN (CP-EN) if the initial $\mathrm{OHC}$ is high. In the present study, the equatorial $\mathrm{OHC}$ early in the year is sometimes higher during the UEN years compared to the CP-EN years. The fact that El Niño fails to develop during the UEN years can be a result of the off-equatorial peaks of SST anomalies that intensify off-equatorial eddies, through enhanced mean wind convergence and shear and active convection, leading to the absence of WWBs near the equator. The high-OHC regions do not correspond to the regions of the SST warming in the CP-EN and UEN years, indicating that the upperocean processes are important in determining the distributions of SST and active atmospheric eddies. The off-equatorial warming and lack of WWBs are also found in 2014 UEN year that drew international attention because of its unpredictable development. Additionally, the presence of a subtropical high in the southeastern Pacific may contribute to the El Niño failure in the UEN years, as southeasterly winds blow into the equatorial region. This may be related to SST cooling in the equatorial central and eastern Pacific through upwelling and/or evaporative cooling, as indicated in the case of the 2014 event (Min et al. 2015; Maeda et al. 2016).

Acknowledgments. The authors would like to thank Takanori Horii, Satoru Yokoi, and Akira Nagano for helpful discussions and Enago (www.enago.jp) for the English language review. Comments from three anonymous reviewers also improved the original manuscript.

\section{REFERENCES}

Ashok, K., S. K. Behera, S. A. Rao, H. Y. Weng, and T. Yamagata, 2007: El Niño Modoki and its possible teleconnection. J. Geophys. Res., 112, C11007, https://doi.org/10.1029/2006JC003798.

Bjerknes, J., 1969: Atmospheric teleconnections from the equatorial Pacific. Mon. Wea. Rev., 97, 163-172, https://doi.org/ 10.1175/1520-0493(1969)097<0163:ATFTEP>2.3.CO;2.
Chen, D., and Coauthors, 2015: Strong influence of westerly wind bursts on El Niño diversity. Nat. Geosci., 8, 339-345, https://doi.org/ 10.1038/ngeo2399.

Eisenman, I., L. Yu, and E. Tziperman, 2005: Westerly wind bursts: ENSO's tail rather than the dog? J. Climate, 18, 5224-5238, https://doi.org/10.1175/JCLI3588.1.

Fedorov, A. V., S. Hu, M. Lengaigne, and E. Guilyardi, 2015: The impact of westerly wind bursts and ocean initial state on the development, and diversity of El Niño events. Climate Dyn., 44, 1381-1401, https://doi.org/10.1007/s00382-014-2126-4.

Gebbie, G., I. Eisenman, A. Wittenberg, and E. Tziperman, 2007: Modulation of westerly wind bursts by sea surface temperature: A semistochastic feedback for ENSO. J. Atmos. Sci., 64, 3281-3295, https://doi.org/10.1175/JAS4029.1.

Giese, B. S., and S. Ray, 2011: El Niño variability in Simple Ocean Data Assimilation (SODA), 1871-2008. J. Geophys. Res., 116, C02024, https://doi.org/10.1029/2010JC006695.

Harrison, D. E., and G. A. Vecchi, 1997: Westerly wind events in the tropical Pacific, 1986-95. J. Climate, 10, 3131-3156, https://doi.org/ 10.1175/1520-0442(1997)010<3131:WWEITT>2.0.CO;2.

Hasegawa, T., and K. Hanawa, 2003: Heat content variability related to ENSO events in the Pacific. J. Phys. Oceanogr., 33, 407-421, https:// doi.org/10.1175/1520-0485(2003)033<0407:HCVRTE > 2.0.CO;2.

Horii, T., I. Ueki, and K. Hanawa, 2012: Breakdown of ENSO predictors in the 2000s: Decadal changes of recharge/ discharge-SST phase relation and atmospheric intraseasonal forcing. Geophys. Res. Lett., 39, L10707, https://doi.org/ 10.1029/2012GL051740.

Imada, Y., H. Tatebe, M. Watanabe, M. Ishii, and M. Kimoto, 2016: South Pacific influence on the termination of El Niño in 2014. Sci. Rep., 6, 30341, https://doi.org/10.1038/srep30341.

Jadhav, J., S. Panickal, S. Marathe, and K. Ashok, 2015: On the possible cause of distinct El Niño types in the recent decades. Sci. Rep., 5, 17009, https://doi.org/10.1038/srep17009.

Jin, F.-F., 1997: An equatorial ocean recharge paradigm for ENSO. Part I: Conceptual model. J. Atmos. Sci., 54, 811-829, https:// doi.org/10.1175/1520-0469(1997)054<0811:AEORPF > 2.0.CO;2.

Kao, H.-Y., and J.-Y. Yu, 2009: Contrasting eastern-Pacific and centralPacific types of ENSO. J. Climate, 22, 615-632, https://doi.org/ 10.1175/2008JCLI2309.1.

Keen, R. A., 1982: The role of cross-equatorial tropical cyclone pairs in the Southern Oscillation. Mon. Wea. Rev., 110, 1405-1416, https:// doi.org/10.1175/1520-0493(1982)110<1405:TROCET>2.0.CO;2.

Kessler, W. S., 1990: Observations of long Rossby waves in the northern tropical Pacific. J. Geophys. Res., 95, 5183-5217, https:// doi.org/10.1029/JC095iC04p05183.

— , M. J. McPhaden, and K. M. Weickmann, 1995: Forcing of intraseasonal Kelvin waves in the equatorial Pacific. J. Geophys. Res., 100, 10 613-10 631, https://doi.org/10.1029/95JC00382.

Kim, H.-M., P. J. Webster, and J. A. Curry, 2009: Impact of shifting patterns of Pacific Ocean warming on North Atlantic tropical cyclones. Science, 325, 77-80, https://doi.org/10.1126/ science. 1174062 .

Knutson, T. R., and K. M. Weickmann, 1987: 30-60 day atmospheric oscillations: Composite life cycles of convection and circulation anomalies. Mon. Wea. Rev., 115, 1407-1436, https://doi.org/ 10.1175/1520-0493(1987)115<1407:DAOCLC > 2.0.CO;2.

Kobayashi, S., and Coauthors, 2015: The JRA-55 Reanalysis: General specifications and basic characteristics. J. Meteor. Soc. Japan, 93, 5-48, https://doi.org/10.2151/jmsj.2015-001.

Kug, J.-S., F.-F. Jin, K. P. Sooraj, and I.-S. Kang, 2008: Statedependent atmospheric noise associated with ENSO. Geophys. Res. Lett., 35, L05701, https://doi.org/10.1029/2007GL032017. 
,$--\frac{\sim}{-}$ and S.-I. An, 2009: Two types of El Niño events: Cold tongue El Niño and warm pool El Niño. J. Climate, 22, 14991515, https://doi.org/10.1175/2008JCLI2624.1.

Larkin, N. K., and D. E. Harrison, 2005: On the definition of El Niño and associated seasonal average U.S. weather anomalies. Geophys. Res. Lett., 32, L13705, https://doi.org/10.1029/2005GL022738.

Lau, K.-H., and N.-C. Lau, 1992: The energetics and propagation dynamics of tropical summertime synoptic-scale disturbances. Mon. Wea. Rev., 120, 2523-2539, https://doi.org/10.1175/ 1520-0493(1992) $120<2523$ :TEAPDO $>2.0$. CO;2.

Lawrence, D. M., and P. J. Webster, 2002: The boreal summer intraseasonal oscillation: Relationship between northward and eastward movement of convection. J. Atmos. Sci., 59, 1593-1606, https://doi.org/10.1175/1520-0469(2002)059<1593: TBSIOR $>2.0 . \mathrm{CO} ; 2$.

Lengaigne, M., J.-P. Boulanger, C. Menkes, S. Masson, G. Madec, and P. Delecluse, 2002: Ocean response to the March 1997 westerly wind event. J. Geophys. Res., 107, 8015, https:// doi.org/10.1029/2001JC000841.

Levine, A. F. Z., and M. J. McPhaden, 2016: How the July 2014 easterly wind burst gave the 2015-16 El Niño a head start. Geophys. Res. Lett., 43, 6503-6510, https://doi.org/10.1002/ 2016GL069204.

Lian, T., and D. Chen, 2012: An evaluation of rotated EOF analysis and its application to tropical Pacific SST variability. J. Climate, 25, 5361-5373, https://doi.org/10.1175/JCLI-D-11-00663.1.

Liebmann, B., H. H. Hendon, and J. D. Glick, 1994: The relationship between tropical cyclones of the western Pacific and Indian Oceans and the Madden-Julian oscillation. J. Meteor. Soc. Japan, 72, 401-412, https://doi.org/10.2151/jmsj1965.72.3_401.

Lin, X., and R. H. Johnson, 1996: Kinematic and thermodynamic characteristics of the flow over the western Pacific warm pool during TOGA COARE. J. Atmos. Sci., 53, 695-715, https:// doi.org/10.1175/1520-0469(1996)053<0695:KATCOT>2.0.CO;2.

Lopez, H., and B. P. Kirtman, 2014: WWBs, ENSO predictability, the spring barrier and extreme events. J. Geophys. Res. Atmos., 119, 10114-10138, https://doi.org/10.1002/2014JD021908.

Madden, R. A., 1986: Seasonal variations of the 40-50 day oscillation in the tropics. J. Atmos. Sci., 43, 3138-3158, https:// doi.org/10.1175/1520-0469(1986)043<3138:SVOTDO >2.0.CO;2.

_ , and P. R. Julian, 1994: Observations of the 40-50-day tropical oscillation-A review. Mon. Wea. Rev., 122, 814-837, https:// doi.org/10.1175/1520-0493(1994)122<0814:OOTDTO>2.0.CO;2.

Maeda, S., Y. Urabe, K. Takemura, T. Yasuda, and Y. Tanimoto, 2016: Active role of the ITCZ and WES feedback in hampering the growth of the expected full-fledged El Niño in 2014. SOLA, 12, 17-21, https://doi.org/10.2151/sola.2016-004.

Maloney, E. D., and D. L. Hartmann, 2000: Modulation of eastern North Pacific hurricanes by the Madden-Julian oscillation. J. Climate, 13, 1451-1460, https://doi.org/10.1175/ 1520-0442(2000)013<1451:MOENPH > 2.0.CO;2.

_ , and M. J. Dickinson, 2003: The intraseasonal oscillation and the energetics of summertime tropical western North Pacific synoptic-scale disturbances. J. Atmos. Sci., 60, 2153-2168, https:// doi.org/10.1175/1520-0469(2003)060<2153:TIOATE >2.0.CO;2.

McPhaden, M. J., 2004: Evolution of the 2002/03 El Niño. Bull. Amer. Meteor. Soc., 85, 677-695, https://doi.org/10.1175/BAMS-85-5-677. , 2015: Playing hide and seek with El Niño. Nat. Climate Change, 5, 791-795, https://doi.org/10.1038/nclimate2775. , and B. A. Taft, 1988: Dynamics of seasonal and intraseasonal variability in the eastern equatorial Pacific. J. Phys. Oceanogr., 18, 1713-1732, https://doi.org/10.1175/1520-0485(1988)018<1713: DOSAIV $>2.0 . \mathrm{CO} ; 2$
— T. Lee, and D. McClurg, 2011: El Niño and its relationship to changing background conditions in the tropical Pacific Ocean. Geophys. Res. Lett., 38, L15709, https://doi.org/10.1029/ 2011 GL048275.

Meinen, C. S., and M. J. McPhaden, 2000: Observations of warm water volume changes in the equatorial Pacific and their relationship to El Niño and La Niña. J. Climate, 13, 3551-3559, https://doi.org/ 10.1175/1520-0442(2000)013<3551:OOWWVC >2.0.CO;2.

Menkes, C. E., M. Lengaigne, J. Vialard, M. Puy, P. Marchesiello, S. Cravatte, and G. Cambon, 2014: About the role of westerly wind events in the possible development of an El Niño in 2014. Geophys. Res. Lett., 41, 6476-6483, https://doi.org/10.1002/2014GL061186.

Min, Q., J. Su, R. Zhang, and X. Rong, 2015: What hindered the El Niño pattern in 2014? Geophys. Res. Lett., 42, 6762-6770, https://doi.org/10.1002/2015GL064899.

Nakazawa, T., 1988: Tropical super clusters within intraseasonal variations over the western Pacific. J. Meteor. Soc. Japan, 66, 823-839, https://doi.org/10.2151/jmsj1965.66.6_823.

Nitta, T., 1989: Development of a twin cyclone and westerly bursts during the initial phase of the 1986-87 El Niño. J. Meteor. Soc. Japan, 67, 677-681, https://doi.org/10.2151/jmsj1965.67.4_677.

—, T. Mizuno, and K. Takahashi, 1992: Multi-scale convective systems during the initial phase of the 1986/87 El Niño. J. Meteor. Soc. Japan, 70, 447-466, https://doi.org/10.2151/ jmsj1965.70.1B_447.

Picaut, J., F. Masia, and Y. du Penhoat, 1997: An advectivereflective conceptual model for the oscillatory nature of the ENSO. Science, 277, 663-666, https://doi.org/10.1126/ science.277.5326.663.

Power, S., T. Casey, C. Folland, A. Colman, and V. Mehta, 1999: Inter-decadal modulation of the impact of ENSO on Australia. Climate Dyn., 15, 319-324, https://doi.org/10.1007/ s003820050284.

Puy, M., J. Vialard, M. Lengaigne, and E. Guilyardi, 2016: Modulation of equatorial Pacific westerly/easterly wind events by the Madden-Julian oscillation and convectively-coupled Rossby waves. Climate Dyn., 46, 2155-2178, https://doi.org/ 10.1007/s00382-015-2695-x.

Ren, H.-L., and F.-F. Jin, 2011: Niño indices for two types of ENSO. Geophys. Res. Lett., 38, L04704, https://doi.org/ 10.1029/2010GL046031.

Reynolds, R. W., T. M. Smith, C. Liu, D. B. Chelton, K. S. Casey, and M. G. Schlax, 2007: Daily high-resolution-blended analysis for sea surface temperature. J. Climate, 20, 5473-5496, https://doi.org/10.1175/2007JCLI1824.1.

Schopf, P. S., and M. J. Suarez, 1988: Vacillations in a coupled oceanatmosphere model. J. Atmos. Sci., 45, 549-566, https://doi.org/ 10.1175/1520-0469(1988)045<0549:VIACOM > 2.0.CO;2.

Seiki, A., and Y. N. Takayabu, 2007a: Westerly wind bursts and their relationship with intraseasonal variations and ENSO. Part I: Statistics. Mon. Wea. Rev., 135, 3325-3345, https:// doi.org/10.1175/MWR3477.1.

_, and - 2007b: Westerly wind bursts and their relationship with intraseasonal variations and ENSO. Part II: Energetics over the western and central Pacific. Mon. Wea. Rev., 135, 3346-3361, https://doi.org/10.1175/MWR3503.1.

,,-- K. Yoneyama, N. Sato, and M. Yoshizaki, 2009: The oceanic response to the Madden-Julian oscillation and ENSO. SOLA, 5, 93-96, https://doi.org/10.2151/sola.2009-024.

Slingo, J. M., D. P. Rowell, K. R. Sperber, and F. Nortley, 1999: On the predictability of the interannual behaviour of the Madden-Julian oscillation and its relationship with El Niño. Quart. J. Roy. Meteor. Soc., 125, 583-609, https://doi.org/10.1002/qj.49712555411. 
Sobel, A. H., and C. S. Bretherton, 1999: Development of synopticscale disturbances over the summertime tropical northwest Pacific. J. Atmos. Sci., 56, 3106-3127, https://doi.org/10.1175/ 1520-0469(1999)056<3106:DOSSDO>2.0.CO;2.

Straub, K. H., 2013: MJO initiation in the real-time multivariate MJO index. J. Climate, 26, 1130-1151, https://doi.org/10.1175/ JCLI-D-12-00074.1.

Sui, C.-H., and K.-M. Lau, 1992: Multiscale phenomena in the tropical atmosphere over the western Pacific. Mon. Wea. Rev., 120, 407-430, https:/doi.org/10.1175/1520-0493(1992)120<0407:MPITTA>2.0.CO;2.

Takahashi, K., A. Montecinos, K. Goubanova, and B. Dewitte, 2011: ENSO regimes: Reinterpreting the canonical and Modoki El Niño. Geophys. Res. Lett., 38, L10704, https://doi. org/10.1029/2011GL047364.

Wang, B., and H. Rui, 1990: Synoptic climatology of transient tropical intraseasonal convection anomalies: 1975-1985. Meteor. Atmos. Phys., 44, 43-61, https://doi.org/10.1007/BF01026810.

Webster, P. J., and H.-R. Chang, 1988: Equatorial energy accumulation and emanation regions: Impacts of a zonally varying basic state. J. Atmos. Sci., 45, 803-829, https://doi.org/10.1175/ 1520-0469(1988)045<0803:EEAAER >2.0.CO;2.

Weisberg, R. H., and C. Wang, 1997: A western Pacific oscillator paradigm for the El Niño-Southern Oscillation. Geophys. Res. Lett., 24, 779-782, https://doi.org/10.1029/97GL00689.
Weng, H., S. K. Behera, and T. Yamagata, 2009: Anomalous winter climate conditions in the Pacific Rim during recent El Niño Modoki and El Niño events. Climate Dyn., 32, 663-674, https:// doi.org/10.1007/s00382-008-0394-6.

Wheeler, M. C., and H. H. Hendon, 2004: An all-season real-time multivariate MJO index: Development of an index for monitoring and prediction. Mon. Wea. Rev., 132,1917-1932, https://doi. org/10.1175/1520-0493(2004)132<1917:AARMMI>2.0.CO;2.

Wyrtki, K., 1975: El Niño-The dynamic response of the equatorial Pacific Ocean to atmospheric forcing. J. Phys. Oceanogr., 5, 572-584, https://doi.org/10.1175/1520-0485(1975)005<0572: ENTDRO $>2.0 . \mathrm{CO} ; 2$.

Zebiak, S. E., 1989: Oceanic heat content variability and El Niño cycles. J. Phys. Oceanogr., 19, 475-486, https://doi.org/10.1175/ 1520-0485(1989)019<0475:OHCVAE > 2.0.CO;2.

Zhang, C., 2005: Madden-Julian oscillation. Rev. Geophys., 43, RG2003, https://doi.org/10.1029/2004RG000158.

_ , and M. Dong, 2004: Seasonality in the Madden-Julian oscillation. J. Climate, 17, 3169-3180, https://doi.org/10.1175/ 1520-0442(2004)017<3169:SITMO>2.0.CO;2.

Zhou, L., A. H. Sobel, and R. Murtugudde, 2012: Kinetic energy budget for the Madden-Julian oscillation in a multiscale framework. J. Climate, 25, 5386-5403, https://doi.org/10.1175/ JCLI-D-11-00339.1. 